Following is the Accepted Version of the article

Domen Šeruga and Marko Nagode (2019)

A new approach to finite element modelling of cyclic thermomechanical stress-strain responses

published by

International Journal of Mechanical Sciences.

The formal publication can be accessed at

https://doi.org/10.1016/ji.ijmecsci.2019.105139.

This version of the article may be used for non-commercial purposes in accordance with Elsevier's Green open access policy (CC-BY-NC-ND license). 


\title{
A new approach to finite element modelling of cyclic thermomechanical stress-strain responses
}

\author{
Domen Šeruga*, Marko Nagode \\ University of Ljubljana, Faculty of Mechanical Engineering, Ljubljana, Slovenia
}

\begin{abstract}
Modern finite element based structural analyses of thermomechanically loaded structures require accurate simulations with low computational times. However, increasing the complexity of material models capable of modelling cyclic phenomena of engineering materials usually also increases the computational time. Here we present the implementation of the Prandtl operator approach into a finite element solver as a new material model for the study of the stress-strain response of solids subjected to thermomechanical loading. The main advantage of this model is its high computational speed, due mainly to the implicit consideration of the Masing and memory rules by variable temperatures, either during a single load cycle or during a complex thermomechanical load history. The model enables temperature-dependent elastoplastic stress-strain modelling using the von Mises yield function, associated flow rule and multilinear kinematic hardening. The commonly used elastic predictor-plastic corrector procedure now contains an improvement in the calculation of the equivalent plastic strain increment. This includes modelling of the true stress by the time-efficient temperature-dependent spring-slider model. The second advantage of the approach is a reduced number of material parameters per temperature required by the Ramberg-Osgood-type description of the cyclic curve. These material parameters can be obtained from either uniaxial strain controlled low cycle fatigue tests or uniaxial incremental step tests. The model has been validated on several load cases of both a thermomechanically loaded single finite element under tension-compression and shear loads, and a cantilever beam subjected to bending loads. Comparisons with reference material models show almost identical behaviour of the new and the Besseling model, but with the advantage of having up to 35 percent shorter computation times.
\end{abstract}

Keywords:

Prandtl operators, finite element method, thermomechanical loading, plasticity, uniaxial, fatigue 


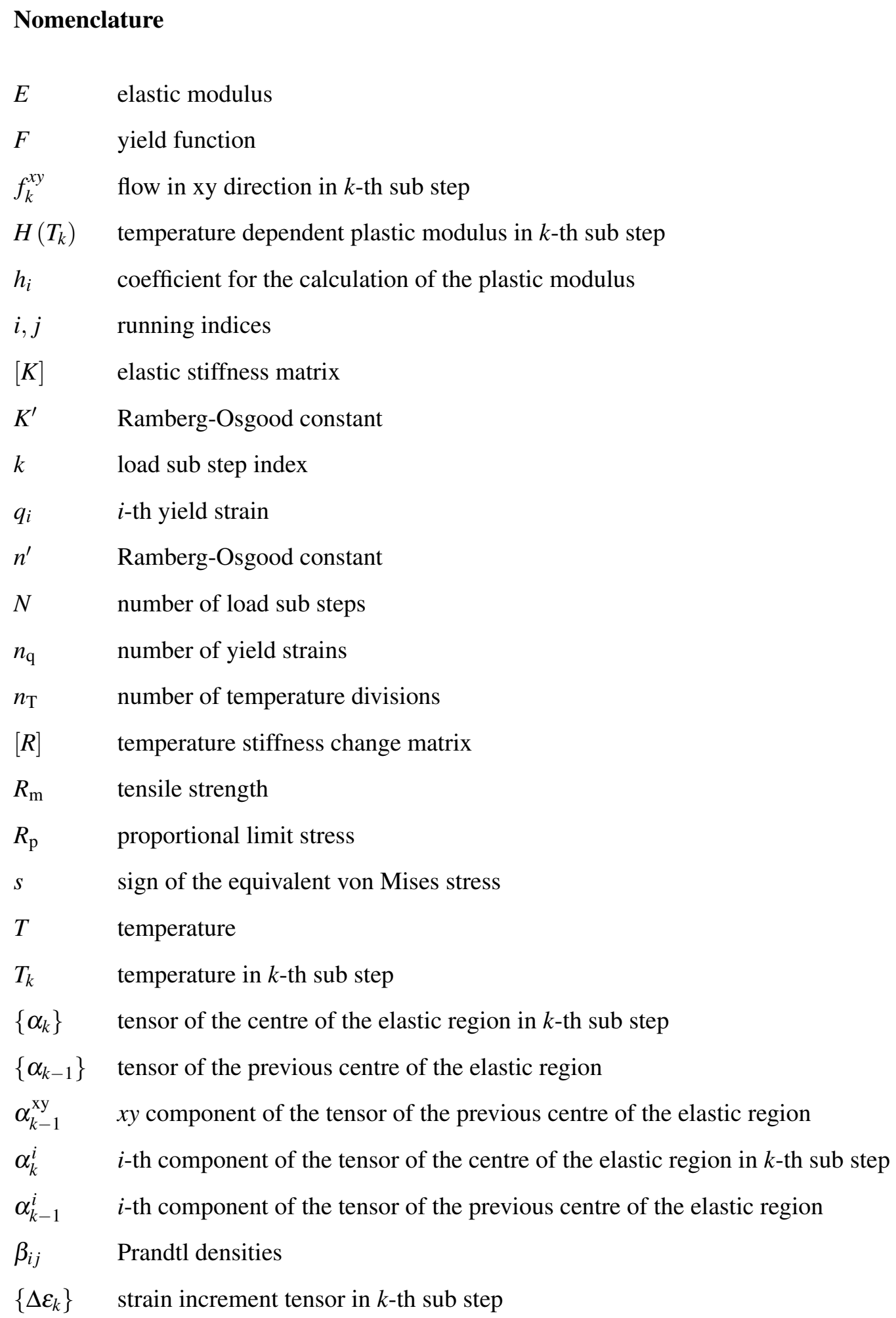

$\left\{\Delta \varepsilon_{k}\right\} \quad$ strain increment tensor in $k$-th sub step 
$\Delta \varepsilon_{k j}^{\mathrm{eq}, \mathrm{pl}} \quad$ equivalent plastic strain increment in $k$-th sub step and $j$-th iteration step

$\Delta \varepsilon_{k}^{\mathrm{xy}} \quad x y$ component of the strain increment tensor

$\left\{\varepsilon_{k}\right\} \quad$ strain tensor in $k$-th sub step

$\left\{\varepsilon_{k-1}\right\} \quad$ strain tensor from the previously converged sub step

$\varepsilon_{k-1}^{\mathrm{xy}} \quad x y$ component of the strain tensor from the previously converged sub step

$\left\{\varepsilon_{k}^{\mathrm{el}}\right\} \quad$ elastic strain tensor in $k$-th sub step

$\left\{\varepsilon_{k-1}^{\mathrm{el}}\right\} \quad$ elastic strain tensor from the previously converged sub step

$\varepsilon_{k-1}^{\mathrm{el}, \mathrm{xy}} \quad x y$ component of the elastic strain tensor from the previously converged sub step

$\varepsilon_{k}^{\mathrm{eq}, \mathrm{pl}} \quad$ equivalent plastic strain in $k$-th sub step

$\varepsilon_{k-1}^{\text {eq,pl }} \quad$ equivalent plastic strain from the previously converged sub step

$\left\{\varepsilon_{k}^{\mathrm{el}, \mathrm{pr}}\right\} \quad$ elastic strain predictor in $k$-th sub step

$\left\{\varepsilon_{k}^{\mathrm{pl}}\right\} \quad$ plastic strain tensor in $k$-th sub step

$\varepsilon_{y} \quad$ yield strain

$\varepsilon_{\beta i}^{k} \quad i$-th back-strain in $k$-th sub step

$\varepsilon_{\beta i}^{k-1} \quad i$-th back-strain from the previously converged sub step

$v \quad$ Poisson's ratio

$\left\{\sigma_{k}\right\} \quad$ stress tensor in $k$-th sub step

$\left\{\sigma_{k-1}\right\} \quad$ stress tensor from the previously converged sub step

$\sigma_{k-1}^{\mathrm{xy}} \quad x y$ component of the stress tensor from the previously converged sub step

$\left\{\sigma_{k}^{\mathrm{el}, \mathrm{pr}}\right\}$ elastic stress predictor in $k$-th sub step

$\sigma_{k}^{\mathrm{el}, \mathrm{xy}} \quad x y$ component of the elastic stress predictor

$\sigma_{k}^{\mathrm{H}} \quad$ hydrostatic pressure

$\sigma_{k}^{\mathrm{N}} \quad$ hydrostatic pressure from the last sub step of the previous load step

$\sigma_{k}^{\mathrm{O}} \quad$ uniaxial stress, modelled by the Prandtl operator in $k$-th sub step

$\sigma_{k-1}^{\mathrm{O}} \quad$ uniaxial stress, modelled by the Prandtl operator from the previously converged sub step

$\sigma_{k}^{\mathrm{VM}} \quad$ equivalent von Mises stress

$\sigma_{y} \quad$ yield stress

$\zeta \quad$ convergence coefficient

$\frac{\partial \Delta \sigma}{\partial \Delta \varepsilon} \quad$ Jacobian matrix 


\section{Introduction}

Thermomechanically loaded metallic mechanical components, such as cylinder heads, crankcases, exhaust manifolds or other hot parts of the exhaust system, gas turbines and power plants operate under very demanding conditions [1-10]. Such conditions can cause considerable plastic deformation of a component due to either high mechanical loads or moderate mechanical loads combined with elevated temperatures, both of which exceed the yield stress of the material [2,11-13]. If plastic deformation varies due to variable work conditions (start-up, full and partial loads, shut-down), the component is subjected to low-cycle fatigue which can eventually result in failure $[2,6,14]$.

During variable mechanical loading at constant or variable temperature, the stress-strain behaviour of metallic materials follows several rules, as shown in Fig. 1 [15]. When the material is loaded above the yield stress for the first time, the stress-strain behaviour follows a static tensile-compressive curve (Fig. 1a). If the load is reversed and returned to the original state a number of times, the material is considered to cyclically harden or soften (Fig. 1a). If constant load levels of various sizes are followed, a stabilised cyclic stress-strain curve is observed where cyclically hardened or softened reversal points for that material are connected (Fig. 1b). For a stabilised material response, it is assumed that the stress-strain behaviour follows the stabilised cyclic stress-strain curve even when the material is loaded for the first time [16]. This assumption simplifies the simulation of the stress-strain response during variable mechanical loading at constant temperature. The stress-strain paths between reversal points on the stabilised cyclic stress-strain curve, named stabilised hysteresis loops, consist of tensile and compressive branches (Fig. 1b). They describe the Bauschinger effect, i.e. kinematic hardening of metallic materials, and can be mathematically expressed by the Masing rule using a modified equation of the stabilised cyclic curve $[16,17]$. If a compressive hysteresis branch is started from the stabilised cyclic curve, the tensile branch will follow the stabilised cyclic curve once the hysteresis loop is closed (memory rule M1 in Fig. 1c). Similarly, a compressive branch of a nested hysteresis loop will follow the compressive branch of the original hysteresis loop once a nested hysteresis loop is closed (memory rule M2 in Fig. 1c). Finally, if the compressive load exceeds the absolute value of the maximum tensile load in the load history, the compressive branch of a hysteresis loop will follow the stabilised cyclic stress-strain curve in the compressive direction (memory rule M3 in Fig. 1c). The same rules apply also to tensile hysteresis branches that start from either a stabilised cyclic stress-strain curve or a hysteresis branch. If the temperature is not constant during variable mechanical loading, the memory rules become unclear as the closure points of the hysteresis loops float in stress-strain space depending on the 
temperature (Fig. 1d) [18].
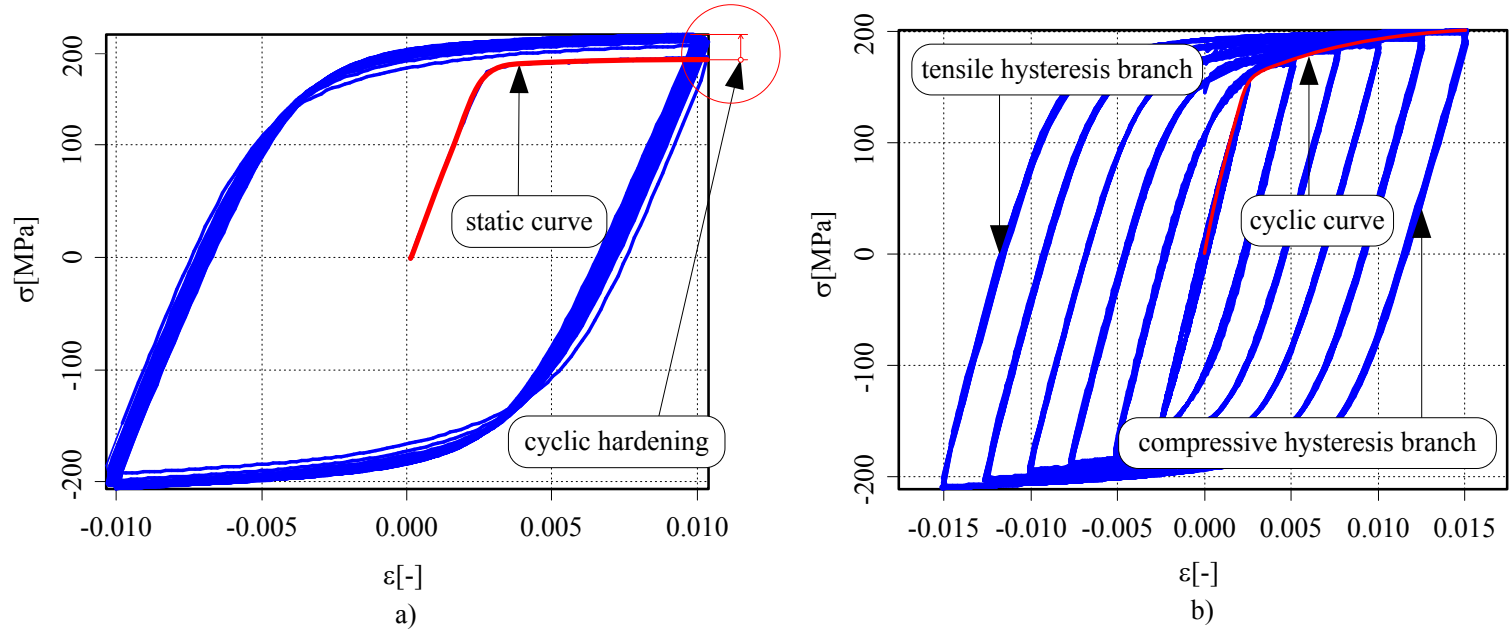

$\mathrm{T}\left[{ }^{\circ} \mathrm{C}\right]$

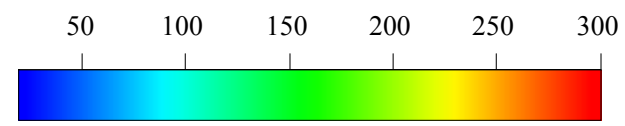

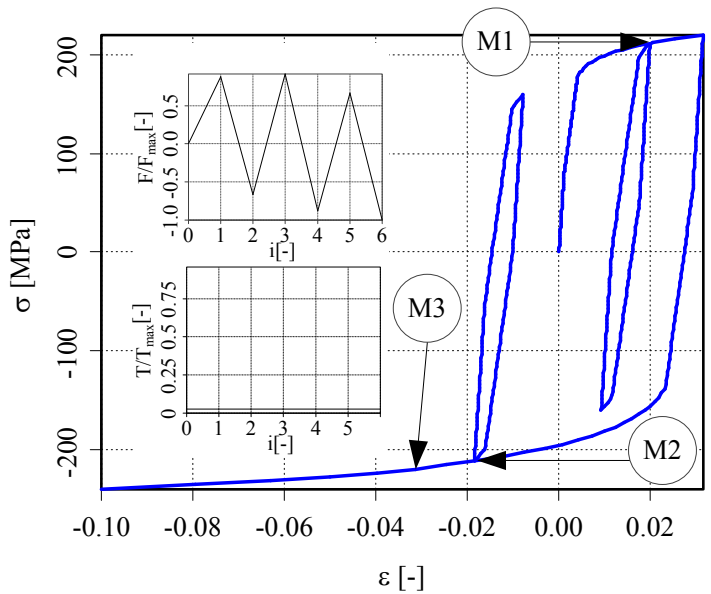

c)

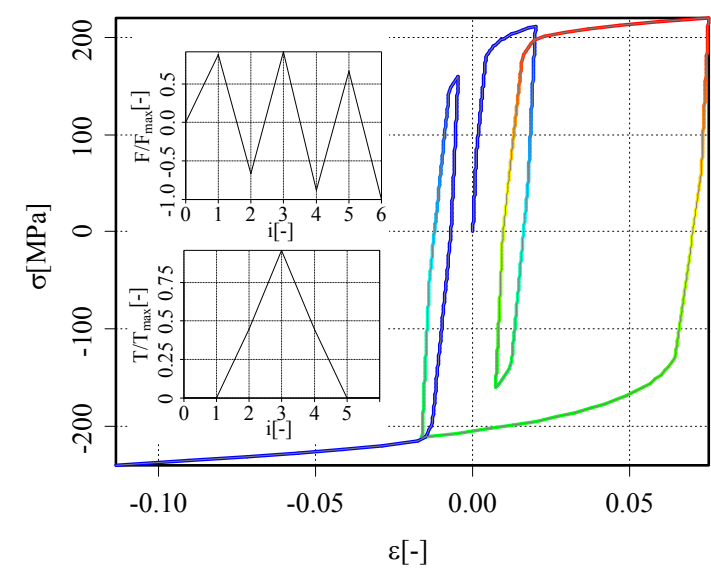

d)

Figure 1: Stress-strain behaviour of aluminium alloy AlMgSi0.5 during variable mechanical loading for a) initial or cyclic loading, b) determination of the stabilised cyclic curve, c) memory rules M1, M2 and M3 and d) variable temperature.

The design process of thermomechanically loaded components should consider the issue of durability in the early stages of development [2]. However, efficient durability predictions can only be performed if the following conditions are assured: accurate simulations of the stress-strain response, accurate damage calculation and reliable material testing $[9,11,19,20]$. Accurate simulations must determine such tem- 
perature, stress-strain and damage distribution over the mechanical component as would be observed if they were measured experimentally. Reliable material testing first involves good control and monitoring of test conditions, such as strain rate and strain limits, a constant temperature environment at pre-chosen temperature levels and accurate stress measurements $[7,21]$. To achieve trustworthy test results, standard test procedures can be followed such as ASTM E606 / E606M - 12. Next, the results of material testing have to be statistically evaluated with average values and confidence limits [19]. Finally, parameters for the material models are determined for the chosen confidence interval and these material models are then included in the simulations. Finite element (FE) based calculations are mostly used for the simulations of the temperature dependent stress-strain response and damage accumulation $[3,12,22]$.

This paper addresses the stress-strain simulation aspect of durability predictions. Furthermore, it describes a FE implementation of the Prandtl operator approach which has been introduced for simulations of temperature dependent stress-strain behaviour. To characterise the elastoplastic response of metals subjected to cyclic loadings, three conventional models of kinematic hardening are predominantly used. These comprise bilinear, multilinear or nonlinear hardening. Bilinear kinematic hardening was first introduced by Melan and Prager and presented the simplest description of the Bauschinger effect [23-25]. Ziegler then adapted the Melan-Prager model so that it was more convenient for use [26]. However, for a detailed description of the stress-strain behaviour, the Melan-Prager or Ziegler models proved insufficient. The multilinear Besseling model turned out to be an adequate choice to describe the kinematic hardening of metals but the computational speed of the model is affected by increasing the number of discretisation points on the cyclic curve [27]. The nonlinear description of the kinematic hardening introduced by Armstrong and Frederick follows an exponential model of hardening. However, its computational speed is influenced by the complex description of the stress-strain behaviour [28]. Various other material models exist which enable simulations of the elastoplastic response of metals subjected to cyclic loadings, e.g. [13, 29-34]. The main advantages of the Prandtl operator approach as compared to conventional models are: the inclusion of rules for the cyclic behaviour of metallic materials (Fig. 1) for both constant and variable temperature; and high computational speed as the material parameters are calculated and stored prior to the simulations [35]. The Prandtl operator approach incorporates the Ramberg-Osgood (RO) description of the cyclic curve [36], the Masing rule to describe the hysteresis branches and rainflow counting with memory rules to consider the nested cycles $[18,35]$. A more detailed description of the contemporary development of the Prandtl operator approach is given in $[2,18,35,37]$. Though initially designed for elastoplastic material modelling [18], the 
model has been extended to include viscoplastic effects [37] or transformed so as to calculate cyclic damage evolution considering signed von Mises, critical plane or energy criteria [37, 38]. Durability predictions of thermomechanically loaded components using the Prandtl operator approach have been validated to date on several mechanical components including exhaust mufflers, a turbocharger housing, a forging tool and an air-spring $[2,37,39,40]$.

However, the non-FE implemented Prandtl operator approach requires providing either stress tensor or elastoplastic strain tensor and temperature to model the stress-strain response during thermomechanical cyclic loading [35]. As the Prandtl operator approach has not been available as a material model within a FE solver such as Abaqus, Ansys or similar, the generation of the input quantity still involves simulations using the FE method using one of the available material models for elastoplastic or viscoplastic material behaviour. These models enable either bilinear, multilinear or nonlinear material behaviour with several hardening laws. Besseling or Armstrong-Frederick models $[7,27,28]$ are especially suitable for either a multilinear or a nonlinear description of the cyclic curve although they either do not match the RO equation completely as the constitutive equations can be based on different mathematical laws or the temperature influence can be considered variously between the models [41]. Moreover, an extensive amount of finite elements can also influence the computational times of simulations. Nevertheless, stress-strain simulations using the FE method result in multiaxial stress and strain tensors which must be compatible with the temperature-dependent RO description of the cyclic curve used later in the non-FE implemented Prandtl operator approach otherwise discrepancies in the durability predictions are to be expected.

Due to the unification of the non-FE implemented and FE-implemented material modelling and the advantages of the Prandtl operator approach, it has now been transformed into a form appropriate for implementation into a FE solver. The FE-implemented Prandtl operator approach presented here uses the RO description of the cyclic curve, a von Mises yield function and associated flow rule for yielding [7, 15, 42, 43]. Other performances such as the Masing rule and rainflow counting with memory rules also remain an integral part of the approach. The von Mises yield function is one of the most commonly used yield functions to simulate plasticity of metals $[13,15,32,42,44,45]$. It enables transformation of a multi-axial stress state into a scalar value which can then be compared to the yield stress observed during a uniaxial test of the material under investigation. Amongst others, Ding et al. [46] used it to simulate cyclic behaviour of a brick-shaped specimen made of 316L stainless steel subjected to bending loads and Roostaei et al. [47] proved its applicability on various magnesium alloys. The associated flow rule describes the material be- 
haviour after plastic yielding and has been used extensively for metals such as mild steel, high strength steel, stainless steel, aluminium alloys or magnesium alloys [12, 15, 47, 48]. Kinematic hardening is the ruling mechanism especially for steels with high yield strengths as isotropic hardening is stabilised after several initial cycles as shown in a study by Silvestre et al. [15].

Through the rest of the paper, the FE-implemented Prandtl operator approach will be referred to as the Prandtl model and the material behaviour using the Besseling model and the AF model will be referred to as Reference models 1 and 2 during the validation section, respectively.

\section{Method using the Prandtl model}

Initially the elastic modulus $E=E(T)$, Poisson's coefficient $v=v(T)$ and Ramberg Osgood's coefficients $K^{\prime}=K^{\prime}(T)$ and $n^{\prime}=n^{\prime}(T)$ are provided as temperature dependent input data. The yield strains $q_{i} ; i=1, \ldots, n_{\mathrm{q}}$ and the Prandtl densities $\beta_{i j} ; i=1, \ldots, n_{\mathrm{q}} ; j=1, \ldots, n_{\mathrm{T}}$ are then calculated prior to the stressstrain simulation and stored in order to maintain a high computational speed of the simulation. The reader is referred to $[18,35]$ for further details on the yield strains and the Prandtl density calculation. A solid is meshed with finite elements which are interconnected by nodes. Each finite element contains a number of integration points in which the stresses and the strains are calculated as a reaction to the external thermomechanical load. The calculation shown below is performed on every integration point of every finite element in the model. Furthermore, the temperature field applied to the model influences the values of the material parameters. However, for clarity of presentation the indices for the finite element, the integration point and the temperature are omitted. Only where these indices are crucial for the calculation are they explicitly pointed out. It is assumed that the calculation consists of several load steps in which both the mechanical loads and the temperatures are applied. Every load step is further divided into several sub steps to ensure a smooth transition between successive loads.

An arbitrary load step is chosen which is divided into $k=1, \ldots, N$ sub steps. If a $k$-th sub step of the load step is observed, the strain increment $\left\{\Delta \varepsilon_{k}\right\}=\left\{\Delta \varepsilon_{k}^{\mathrm{xx}}, \Delta \varepsilon_{k}^{\mathrm{yy}}, \Delta \varepsilon_{k}^{\mathrm{zz}}, \Delta \varepsilon_{k}^{\mathrm{xy}}, \Delta \varepsilon_{k}^{\mathrm{xz}}, \Delta \varepsilon_{k}^{\mathrm{yz}}\right\}^{\mathrm{T}}$ in the $k$-th sub step is estimated based on the previously converged sub step. Next, the elastic stiffness matrix $[K]$ is gained 
as

$$
[K]=\frac{E\left(T_{k}\right)}{\left(1-2 v\left(T_{k}\right)\right)\left(1+v\left(T_{k}\right)\right)}\left[\begin{array}{cccccc}
1-v\left(T_{k}\right) & v\left(T_{k}\right) & v\left(T_{k}\right) & 0 & 0 & 0 \\
v\left(T_{k}\right) & 1-v\left(T_{k}\right) & v\left(T_{k}\right) & 0 & 0 & 0 \\
v\left(T_{k}\right) & v\left(T_{k}\right) & 1-v\left(T_{k}\right) & 0 & 0 & 0 \\
0 & 0 & 0 & \frac{1-2 v\left(T_{k}\right)}{2} & 0 & 0 \\
0 & 0 & 0 & 0 & \frac{1-2 v\left(T_{k}\right)}{2} & 0 \\
0 & 0 & 0 & 0 & 0 & \frac{1-2 v\left(T_{k}\right)}{2}
\end{array}\right]
$$

the temperature stiffness change $[R]$ is calculated as

$$
[R]=[K]-\frac{E\left(T_{k-1}\right)}{\left(1-2 v\left(T_{k-1}\right)\right)\left(1+v\left(T_{k-1}\right)\right)}\left[\begin{array}{cccccc}
1-v\left(T_{k-1}\right) & v\left(T_{k-1}\right) & v\left(T_{k-1}\right) & 0 & 0 & 0 \\
v\left(T_{k-1}\right) & 1-v\left(T_{k-1}\right) & v\left(T_{k-1}\right) & 0 & 0 & 0 \\
v\left(T_{k-1}\right) & v\left(T_{k-1}\right) & 1-v\left(T_{k-1}\right) & 0 & 0 & 0 \\
0 & 0 & 0 & \frac{1-2 v\left(T_{k-1}\right)}{2} & 0 & 0 \\
0 & 0 & 0 & 0 & \frac{1-2 v\left(T_{k-1}\right)}{2} & 0 \\
0 & 0 & 0 & 0 & 0 & \frac{1-2 v\left(T_{k-1}\right)}{2}
\end{array}\right]
$$

and the elastic stress predictor $\left\{\sigma_{k}^{\mathrm{el}, \mathrm{pr}}\right\}$ is worked out as

$$
\begin{aligned}
\left\{\sigma_{k}^{\mathrm{el}, \mathrm{pr}}\right\} & =\left\{\sigma_{k-1}\right\}+[K]\left\{\Delta \varepsilon_{k}\right\}+[R]\left\{\varepsilon_{k-1}^{\mathrm{el}}\right\} \\
& =\left\{\sigma_{k}^{\mathrm{el}, \mathrm{xx}}, \sigma_{k}^{\mathrm{el}, \mathrm{yy}}, \sigma_{k}^{\mathrm{el}, \mathrm{zz}}, \sigma_{k}^{\mathrm{el}, \mathrm{xy}}, \sigma_{k}^{\mathrm{el}, \mathrm{xz}}, \sigma_{k}^{\mathrm{el}, \mathrm{yz}}\right\}^{\mathrm{T}}
\end{aligned}
$$

where $\left\{\sigma_{k-1}\right\}=\left\{\sigma_{k-1}^{\mathrm{xx}}, \sigma_{k-1}^{\mathrm{yy}}, \sigma_{k-1}^{\mathrm{zz}}, \sigma_{k-1}^{\mathrm{xy}}, \sigma_{k-1}^{\mathrm{xz}}, \sigma_{k-1}^{\mathrm{yz}}\right\}^{\mathrm{T}}$ and $\left\{\varepsilon_{k-1}^{\mathrm{el}}\right\}=\left\{\varepsilon_{k-1}^{\mathrm{el}, \mathrm{xx}}, \varepsilon_{k-1}^{\mathrm{el}, \mathrm{yy}}, \varepsilon_{k-1}^{\mathrm{el}, \mathrm{zz}}, \varepsilon_{k-1}^{\mathrm{el}, \mathrm{xy}}, \varepsilon_{k-1}^{\mathrm{el}, \mathrm{xz}}, \varepsilon_{k-1}^{\mathrm{el}, \mathrm{yz}}\right\}^{\mathrm{T}}$ represent the stress and the elastic strain tensors from the previously converged sub step, respectively. The initial values of the stress tensor in the first sub step of the first load step are $\left\{\sigma_{0}\right\}=\{0,0,0,0,0,0\}^{\mathrm{T}}$ or an arbitrary non-zero tensor can be used if an initial stress field is included in the simulation.

The elastic strain predictor $\left\{\varepsilon_{k}^{\mathrm{el}, \mathrm{pr}}\right\}$ is calculated as

$$
\left\{\varepsilon_{k}^{\mathrm{el}, \mathrm{pr}}\right\}=\left\{\varepsilon_{k-1}\right\}+\left\{\Delta \varepsilon_{k}\right\}
$$

where $\left\{\varepsilon_{k-1}\right\}=\left\{\varepsilon_{k-1}^{\mathrm{xx}}, \varepsilon_{k-1}^{\mathrm{yy}}, \varepsilon_{k-1}^{\mathrm{zz}}, \varepsilon_{k-1}^{\mathrm{xy}}, \varepsilon_{k-1}^{\mathrm{xz}}, \varepsilon_{k-1}^{\mathrm{yz}}\right\}^{\mathrm{T}}$ stands for the strain tensor from the previously converged sub step. The initial values of the strain tensor in the first sub step of the first load step are $\left\{\varepsilon_{0}\right\}=\{0,0,0,0,0,0\}^{\mathrm{T}}$ or an arbitrary non-zero tensor can be used if an initial strain field is included in the simulation. The equivalent von Mises stress $\sigma_{k}^{\mathrm{VM}}$ is obtained next from the elastic stress predictor $\left\{\sigma_{k}^{\mathrm{el}, \mathrm{pr}}\right\}$ and the previous centre of the elastic region $\left\{\alpha_{k-1}\right\}$ as

$\sigma_{k}^{\mathrm{VM}}=\sqrt{\frac{\left(\sigma_{k}^{\mathrm{el}, \mathrm{xx}}-\alpha_{k-1}^{\mathrm{xx}}-\sigma_{k}^{\mathrm{el}, y \mathrm{y}}+\alpha_{k-1}^{\mathrm{yy}}\right)^{2}+\left(\sigma_{k}^{\mathrm{el}, y \mathrm{y}}-\alpha_{k-1}^{\mathrm{yy}}-\sigma_{k}^{\mathrm{el}, z \mathrm{zz}}+\alpha_{k-1}^{\mathrm{zz}}\right)^{2}+\left(\sigma_{k}^{\mathrm{el}, \mathrm{zz}}-\alpha_{k-1}^{\mathrm{zz}}-\sigma_{k}^{\mathrm{el}, \mathrm{xx}}+\alpha_{k-1}^{\mathrm{xx}}\right)^{2}+6\left(\left(\sigma_{k}^{\mathrm{el}, \mathrm{xy}}-\alpha_{k-1}^{\mathrm{xy}}\right)^{2}+\left(\sigma_{k}^{\mathrm{el}, \mathrm{xz}}-\alpha_{k-1}^{\mathrm{xz}}\right)^{2}+\left(\sigma_{k}^{\mathrm{el}, y z}-\alpha_{k-1}^{\mathrm{yz}}\right)^{2}\right)}{2}}$ 
The initial values of the centre of the elastic region in the first sub step of the first load step are $\left\{\alpha_{0}\right\}=$ $\{0,0,0,0,0,0\}^{\mathrm{T}}$. Hydrostatic pressure $\sigma_{k}^{\mathrm{H}}$ is determined from the elastic stress predictor $\left\{\sigma_{k}^{\mathrm{el}, \mathrm{pr}}\right\}$ as

$$
\sigma_{k}^{\mathrm{H}}=\frac{\sigma_{k}^{\mathrm{el}, \mathrm{xx}}+\sigma_{k}^{\mathrm{el}, \mathrm{yy}}+\sigma_{k}^{\mathrm{el}, \mathrm{zz}}}{3}
$$

and the sign $s$ of the equivalent von Mises stress $\sigma_{k}^{\mathrm{VM}}$ is computed as

$$
s=\left\{\begin{array}{cc}
1 & \text { if }\left(\sigma_{k}^{\mathrm{H}}-\sigma_{k}^{\mathrm{N}}\right) \geq 0 \\
-1 & \text { if }\left(\sigma_{k}^{\mathrm{H}}-\sigma_{k}^{\mathrm{N}}\right)<0
\end{array}\right.
$$

where $\sigma_{k}^{\mathrm{N}}$ corresponds to hydrostatic pressure from the last sub step of the previous load step. The initial value of $\sigma_{k}^{\mathrm{N}}$ in the first load step is $\sigma_{0}^{\mathrm{N}}=0$. Active yielding is checked by calculating the value of the yield function $F$ as

$$
F=\left(\sigma_{k}^{\mathrm{VM}}-\sigma_{\mathrm{y}}\right)
$$

If $F \leq 0$ in Eq. 8, then the elastic stress predictor $\left\{\sigma_{k}^{\mathrm{el}, \mathrm{pr}}\right\}$ is already the correct solution to the elastic strain predictor $\left\{\varepsilon_{k}^{\mathrm{el}, \mathrm{pr}}\right\}$, so the stress tensor $\left\{\sigma_{k}\right\}$ equals

$$
\left\{\sigma_{k}\right\}=\left\{\sigma_{k}^{\mathrm{el}, \mathrm{pr}}\right\}
$$

and the strain tensor $\left\{\varepsilon_{k}\right\}$ is gained from

$$
\left\{\varepsilon_{k}\right\}=\left\{\varepsilon_{k}^{\mathrm{el}, \mathrm{pr}}\right\}
$$

If $F>0$ in Eq. 8, then yielding occurs. The flow direction $f_{k}^{i}$ is thus calculated as

$$
f_{k}^{i}=\left\{\begin{array}{cl}
\frac{\sigma_{k}^{\mathrm{el}, i}-\alpha_{k-1}^{i}-\sigma_{k}^{\mathrm{H}}}{\sigma_{k}^{\mathrm{VM}}} ; & i=\mathrm{xx}, \mathrm{yy}, \mathrm{zz} \\
\frac{\sigma_{k}^{\mathrm{el}, i}-\alpha_{k-1}^{i}}{\sigma_{k}^{\mathrm{VM}}} ; & i=\mathrm{xy}, \mathrm{xz}, \mathrm{yz}
\end{array}\right.
$$

Next, the equivalent plastic strain increment $\Delta \varepsilon_{k j}^{\mathrm{eq}, \mathrm{pl}}$ is iteratively checked as

$$
\Delta \varepsilon_{k j}^{\mathrm{eq}, \mathrm{pl}}=\Delta \varepsilon_{k j-1}^{\mathrm{eq}, \mathrm{pl}}+\frac{\sigma_{k}^{\mathrm{VM}}-\sigma_{\mathrm{y}}-\frac{3 E\left(T_{k}\right) \Delta \varepsilon_{k j-1}^{\mathrm{eqppl}}}{2\left(1+v\left(T_{k}\right)\right)}-\left|\sigma_{k}^{\mathrm{O}}-\sigma_{k-1}^{\mathrm{O}}\right|}{\frac{3 E\left(T_{k}\right)}{2\left(1+v\left(T_{k}\right)\right)}+H\left(T_{k}\right)} .
$$

Here index $j$ indicates the iteration step and $\sigma_{k}^{\mathrm{O}}$ is the uniaxial stress, modelled by the Prandtl operator as

$$
\sigma_{k}^{\mathrm{O}}=\sum_{i=1}^{n_{\mathrm{q}}} \beta_{i}\left(T_{k}\right) \varepsilon_{\beta i}^{k}
$$




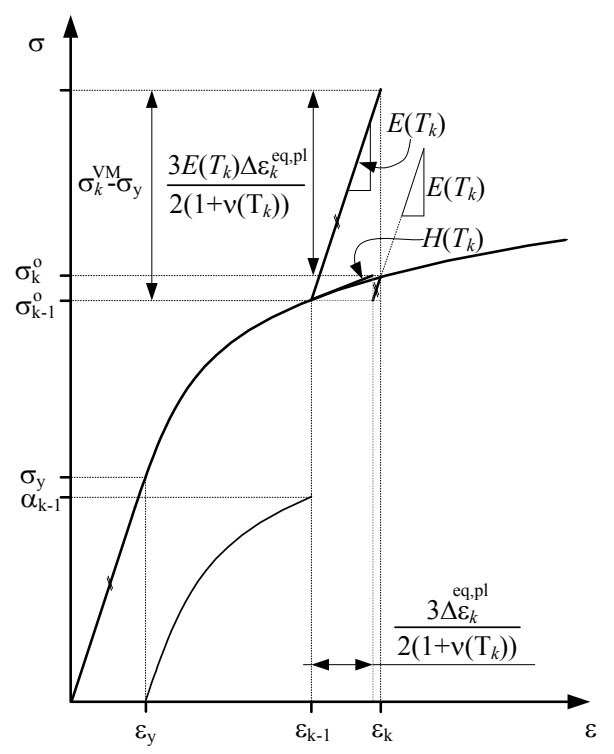

Figure 2: Calculation of the equivalent plastic strain increment $\Delta \varepsilon_{k}^{\mathrm{eq}, \mathrm{pl}}$.

Back-strains $\varepsilon_{\beta i}^{k}$ are determined as

$$
\begin{aligned}
\varepsilon_{\beta i}^{k}= & \max \left\{\varepsilon_{k-1}^{\mathrm{eq}, \mathrm{pl}}+s \Delta \varepsilon_{k j}^{\mathrm{eq}, \mathrm{pl}}-q_{i},\right. \\
& \left.\min \left\{\varepsilon_{k-1}^{\mathrm{eq}, \mathrm{pl}}+s \Delta \varepsilon_{k j}^{\mathrm{eq}, \mathrm{pl}}+q_{i}, \frac{\beta_{i}\left(T_{k-1}\right)}{\beta_{i}\left(T_{k}\right)} \varepsilon_{\beta i}^{k-1}\right\}\right\}
\end{aligned}
$$

where $\varepsilon_{k-1}^{\mathrm{eq}, \mathrm{pl}}$ stands for the equivalent plastic strain from the previously converged sub step. The initial value of the equivalent plastic strain in the first sub step of the first load step is $\varepsilon_{0}^{\text {eq,pl }}=0$. Yield strains are represented by $q_{i}$ whereas $\beta_{i}\left(T_{k-1}\right) ; i=1, \ldots, n_{\mathrm{q}}$ and $\beta_{i}\left(T_{k}\right) ; i=1, \ldots, n_{\mathrm{q}}$ correspond to the Prandtl densities at the temperatures of the integration point in the previously converged and the current sub step, respectively. Uniaxial stress $\sigma_{k-1}^{\mathrm{O}}$ is worked out using Eqs. 13 and 14 for the previously converged sub step with back-strains $\varepsilon_{\beta i}^{k-1}$ and Prandtl densities $\beta_{i}\left(T_{k-1}\right)$. The temperature dependent plastic modulus $H\left(T_{k}\right)$ is calculated as

$$
H\left(T_{k}\right)=\sum_{i=1}^{n_{\mathrm{q}}} h_{i} \beta_{i}\left(T_{k}\right)
$$

where coefficients $h_{i} ; \quad i=1, \ldots, n_{\mathrm{q}}$ are determined as

$$
h_{i}= \begin{cases}0 & \text { if } \varepsilon_{\beta i}^{k}=\frac{\beta_{i}\left(T_{k-1}\right)}{\beta_{i}\left(T_{k}\right)} \varepsilon_{\beta i}^{k-1} \\ 1 & \text { else }\end{cases}
$$


Eq. 12 is solved iteratively with $\Delta \varepsilon_{k 0}^{\mathrm{eq}, \mathrm{pl}}=0$ until the condition

$$
\left|\sigma_{k}^{\mathrm{VM}}-\sigma_{\mathrm{y}}-\frac{3 E\left(T_{k}\right) \Delta \varepsilon_{k j}^{\mathrm{eq}, \mathrm{pl}}}{2\left(1+v\left(T_{k}\right)\right)}-\right| \sigma_{k}^{\mathrm{O}}-\sigma_{k-1}^{\mathrm{O}}||<\zeta \sigma_{\mathrm{y}}
$$

is met, where $\zeta$ represents a small number, e.g. $10^{-6}$. The calculation of the equivalent plastic strain increment $\Delta \varepsilon_{k}^{\mathrm{eq}, \mathrm{pl}}$ is pictorially explained in Fig. 2.

Depending on the position in the $\sigma-\varepsilon$ space, it is observed that the total strain equals the sum of its elastic and plastic components. When the convergence criterion in Eq. 17 is met, the equivalent plastic strain $\varepsilon_{k}^{\text {eq,pl }}$ is computed as

$$
\varepsilon_{k}^{\mathrm{eq}, \mathrm{pl}}=\varepsilon_{k-1}^{\mathrm{eq}, \mathrm{pl}}+s \Delta \varepsilon_{k j}^{\mathrm{eq}, \mathrm{pl}} .
$$

The centre of the elastic region $\left\{\alpha_{k}\right\}$ is updated as

$$
\alpha_{k}^{i}=\alpha_{k-1}^{i}+\left|\sigma_{k}^{\mathrm{O}}-\sigma_{k-1}^{\mathrm{O}}\right| f_{k}^{i} ; \quad i=\mathrm{xx}, \mathrm{yy}, \mathrm{zz}, \mathrm{xy}, \mathrm{xz}, \mathrm{yz}
$$

and the stress tensor $\left\{\sigma_{k}\right\}$ is then obtained from the new centre of the elastic region $\left\{\alpha_{k}\right\}$ as

$$
\sigma_{k}^{i}=\left\{\begin{array}{cc}
\alpha_{k-1}^{i}+\sigma_{\mathrm{y}} f_{k}^{i}+\sigma_{k}^{\mathrm{H}} ; & i=\mathrm{xx}, \mathrm{yy}, \mathrm{zz} \\
\alpha_{k-1}^{i}+\sigma_{\mathrm{y}} f_{k}^{i} ; & i=\mathrm{xy}, \mathrm{xz}, \mathrm{yz} .
\end{array}\right.
$$

The elastic strain tensor $\left\{\varepsilon_{k}^{\mathrm{el}}\right\}$ is determined from the elastic strain predictor $\left\{\varepsilon_{k}^{\mathrm{el}, \mathrm{pr}}\right\}$ as

$$
\varepsilon_{k}^{\mathrm{el}, i}=\left\{\begin{array}{rr}
\varepsilon_{k}^{\mathrm{el}, \mathrm{pr}, i}-\frac{3}{2} f_{k}^{i} \Delta \varepsilon_{k j}^{\mathrm{eq}, \mathrm{pl}} ; & i=\mathrm{xx}, \mathrm{yy}, \mathrm{zz} \\
\varepsilon_{k}^{\mathrm{el}, \mathrm{pr}, i}-f_{k}^{i} \Delta \varepsilon_{k j}^{\mathrm{eq}, \mathrm{pl}} ; & i=\mathrm{xy}, \mathrm{xz}, \mathrm{yz}
\end{array}\right.
$$

and the plastic strain tensor $\left\{\varepsilon_{k}^{\mathrm{pl}}\right\}$ is resolved as

$$
\varepsilon_{k}^{\mathrm{pl}, i}=\left\{\begin{aligned}
\varepsilon_{k-1}^{\mathrm{pl}, i}+\frac{3}{2} f_{k}^{i} \Delta \varepsilon_{k j}^{\mathrm{eq}, \mathrm{pl}} ; & i=\mathrm{xx}, \mathrm{yy}, \mathrm{zz} \\
\varepsilon_{k-1}^{\mathrm{pl}, i}+f_{k}^{i} \Delta \varepsilon_{k j}^{\mathrm{eq}, \mathrm{pl} ;} & i=\mathrm{xy}, \mathrm{xz}, \mathrm{yz}
\end{aligned}\right.
$$

where the values of the plastic strain tensor in the first sub step of the first load step equal $\left\{\varepsilon_{0}^{\mathrm{pl}}\right\}=$ $\{0,0,0,0,0,0\}^{\mathrm{T}}$. Finally, the Jacobian matrix $\frac{\partial \Delta \sigma}{\partial \Delta \varepsilon}$ is determined in the $k$-th sub step for the von Mises 
$\mathrm{J}_{2}$ plasticity [49] which yields

$\frac{\partial \Delta \sigma}{\partial \Delta \varepsilon}=$

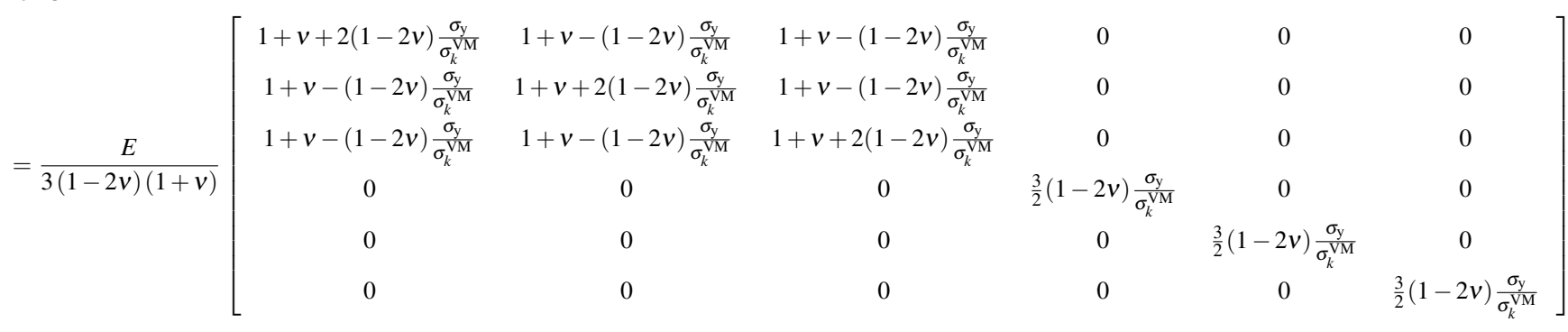

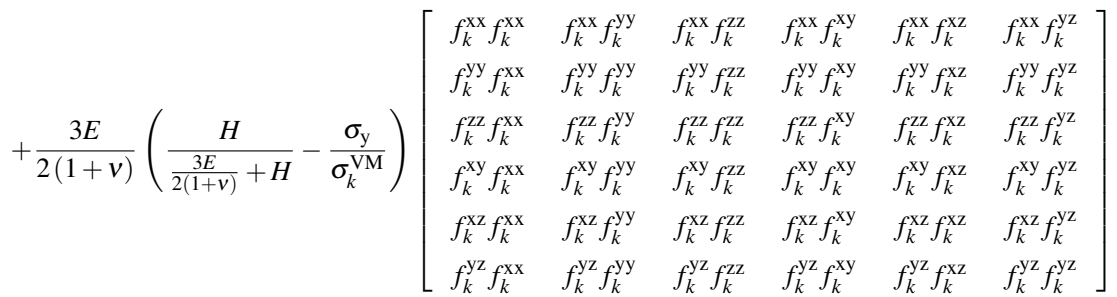

In Eq. 23, elastic modulus, Poisson's coefficient and plastic modulus are temperature dependent, i.e. $E=$ $E\left(T_{k}\right), v=v\left(T_{k}\right)$ and $H=H\left(T_{k}\right)$.

\section{Validation examples}

The method has been validated on six examples. These include four thermomechanical load cases with normal and shear loads on a single finite element and two load cases on a cantilever beam. The method with Prandtl operators has been coded as an Abaqus UMAT subroutine, however another FE solver could be used, e.g. ANSYS Usermat subroutine or similar.

First, a single finite element was loaded at variable temperature by tension and compression as shown in Fig. 3a. The mechanical load was applied either as a displacement or as a force. Thermal loads were added to mechanical loads (as indicated by temperature symbols in Fig. 3. Next, the single finite element was loaded by shear displacement and shear force, respectively, at variable temperatures (Fig. 3b). Finally, a simple cantilever beam consisting of 750 elements and 1224 nodes was loaded by displacement and force in different directions in a varying temperature field (Fig. 3c). Between 0 and $50 \mathrm{~s}$ the mechanical load is applied in the vertical direction and between 50 and $80 \mathrm{~s}$, it is applied in the lateral direction. The load histories for all six validation examples are shown in Fig. 4.

A temperature dependent Prandtl model using cyclic curves divided into 32 yield planes and 500 temperature segments has been used to simulate the material behaviour of the single elements and the cantilever beam. The RO coefficients, tensile strengths and proportional limit stresses are given in Table 1. 

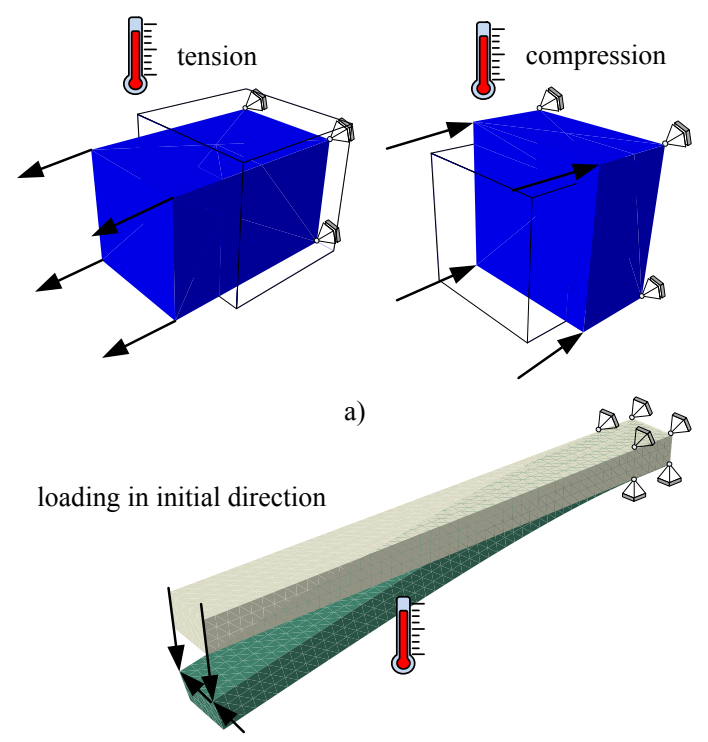

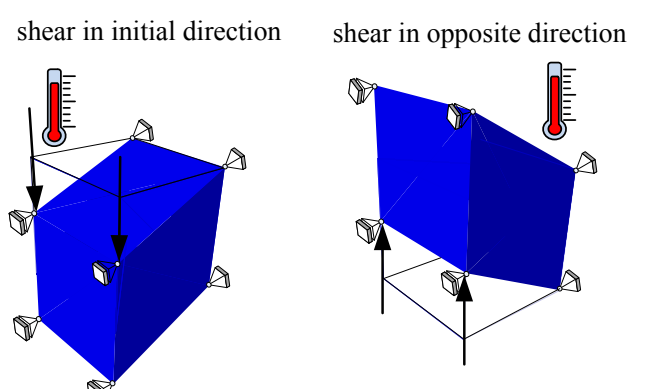

b)

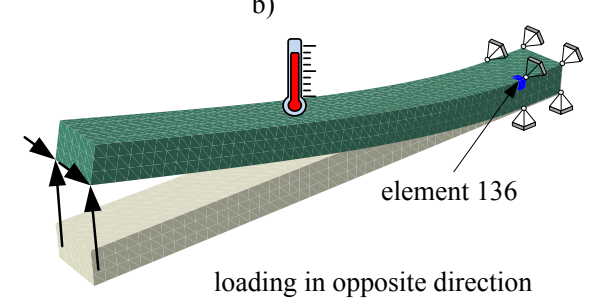

c)

Figure 3: Validation examples: a) a single finite element thermomechanically loaded in tension and compression, b) a single finite element thermomechanically loaded in shear and c) a loaded cantilever beam.

Table 1: Values of the RO coefficients, tensile strengths and proportional limit stresses [41].

\begin{tabular}{cccccc}
$T\left[{ }^{\circ} \mathrm{C}\right]$ & $E[\mathrm{MPa}]$ & $K^{\prime}[\mathrm{MPa}]$ & $n^{\prime}[-]$ & $R_{\mathrm{m}}[\mathrm{MPa}]$ & $\sigma_{\mathrm{p}}[\mathrm{MPa}]$ \\
\hline 20 & 200000 & 603.42 & 0.1211 & 407 & 140 \\
300 & 180000 & 508.16 & 0.1103 & 360 & 120 \\
650 & 150000 & 183.13 & 0.0336 & 165 & 90 \\
\hline
\end{tabular}

As reference models available in Abaqus, the Besseling (Reference model 1) and the Armstrong-Frederick (Reference model 2) models have been used as they enable a temperature dependent elastoplastic material behaviour with either multilinear kinematic or combined isotropic-kinematic hardening, respectively. The cyclic curve for the Besseling model has been discretised into the same number of segments as for the Prandtl model. The AF coefficients have been determined using the Downhill Simplex optimisation method with the additional condition that the kinematic hardening coefficient $\gamma$ is equal for the input temperatures [41]. This ensured comparable RO and AF input curves (Fig. 5) which were then used in the material models of the six examples.

In Figs. $6 \mathrm{a}, 6 \mathrm{~b}, 7 \mathrm{a}$ and $7 \mathrm{~b}$ the axial stress-strain response is represented either as a function of time or as a path in $\sigma-\varepsilon$ space for the single finite element thermomechanically loaded in tension and compression 

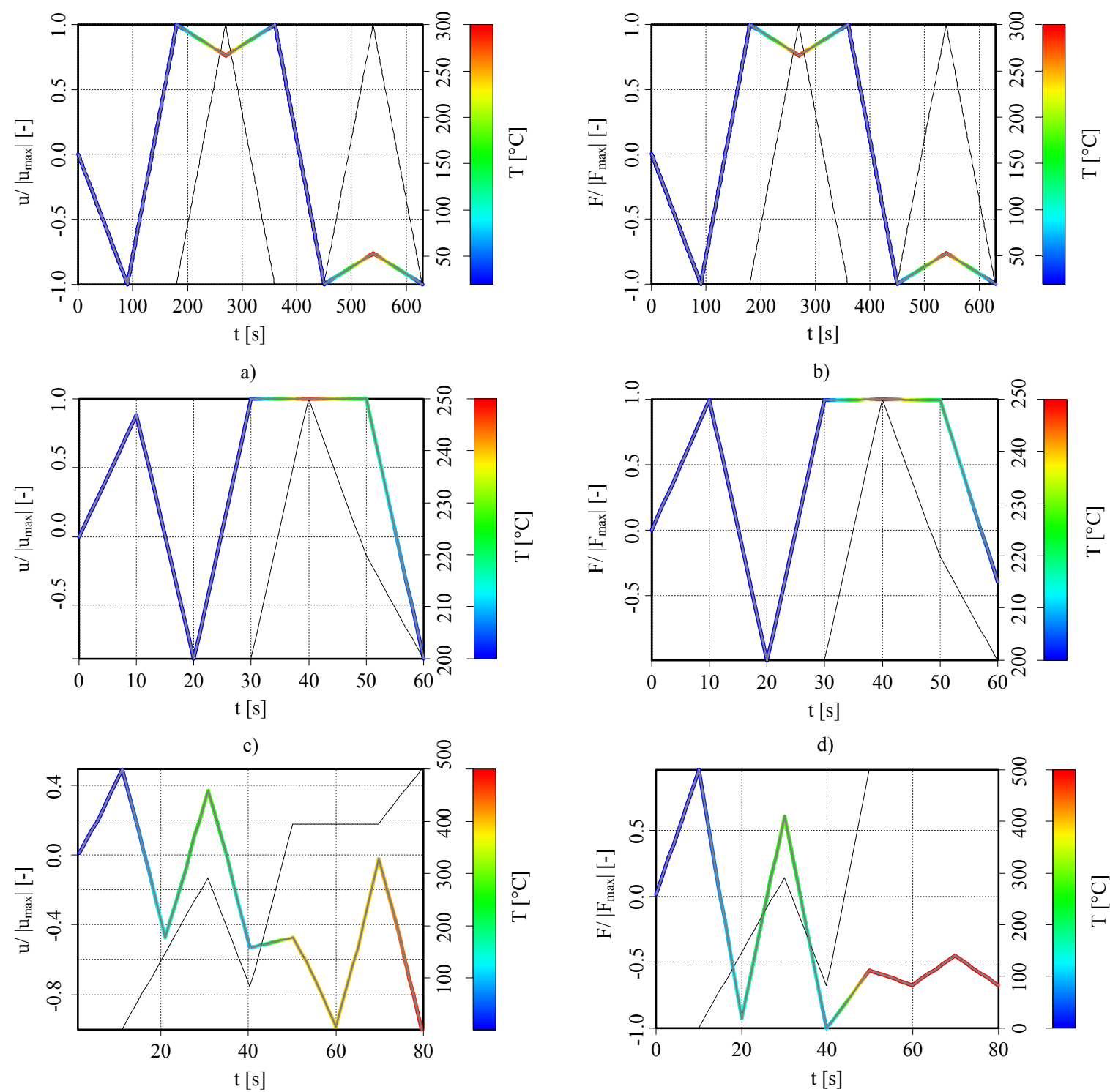

e)

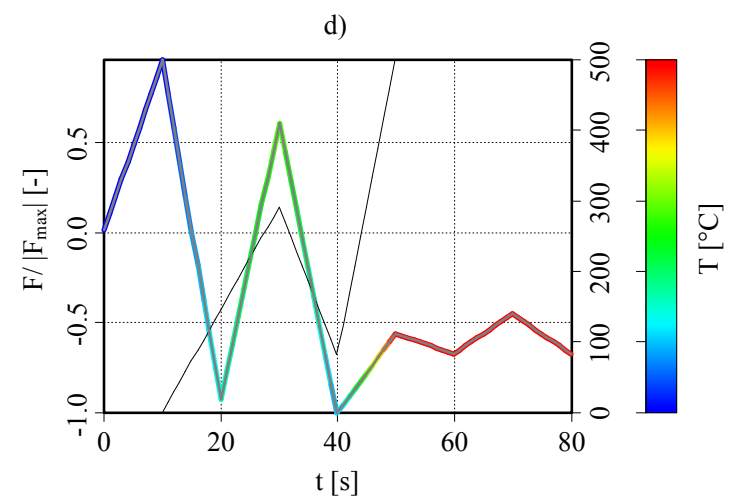

f)

Figure 4: Load histories for a) and b) a single finite element thermomechanically loaded by tension and compression, c) and d) a single finite element thermomechanically loaded by shear and e) and f) a loaded cantilever beam. The grey (coloured) lines represent the mechanical loads and the colours represent temperature. Thin black lines are added for a clearer presentation of the applied temperatures. 


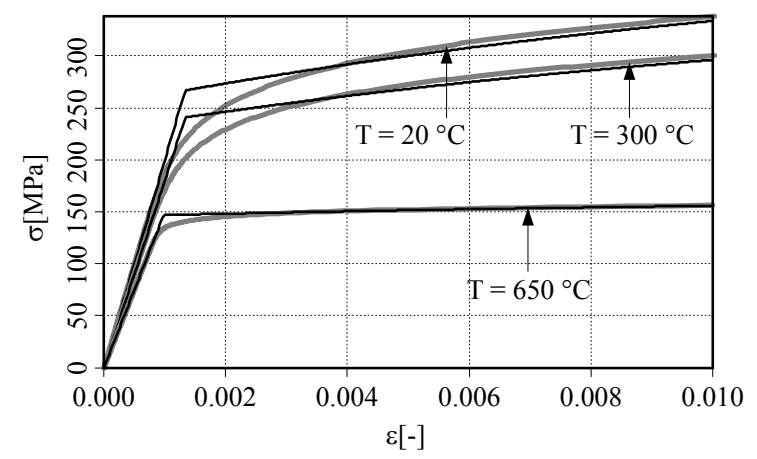

Figure 5: RO (thick grey lines) and AF (thin black lines) input curves for temperatures 20,300 and $650{ }^{\circ} \mathrm{C}$.

as a displacement or as a force. Similarly, in Figs. $6 \mathrm{c}, 6 \mathrm{~d}, 7 \mathrm{c}$ and $7 \mathrm{~d}$ the tangential stress-strain response is represented either as a function of time or as a path in $\sigma-\varepsilon$ space for the single finite element thermomechanically loaded with shear displacement or force. In Figs. 8, 9, 10 and 11, both stress and strain tensors are shown either as functions of time or as paths in $\sigma-\varepsilon$ space for selected finite element 136 (indicated in Fig. 3) when the cantilever beam is loaded by displacement or force.

Computational times for the six examples are given in Table 2. Magnified shape changes during the loading for the single finite elements can be seen in Fig. 3 for both the tension-compression load case and for the shear load case. A magnified shape change and the equivalent stress field in the cantilever beam are shown for every load step in Fig. 12.

\section{Results and discussion}

Both, the Prandtl and Reference model 1 enable simulations of temperature-dependent elastoplastic material behaviour with multilinear kinematic hardening for stabilised cyclic conditions, i.e. it is assumed that isotropic hardening of the material has already reached the level of saturation. However, the form of Reference model 2 to compare the results of the simulations assumes a combined isotropic-kinematic hardening of the material without the possibility of isotropic hardening exclusion. Nevertheless, although a different simulation of the material behaviour is expected due to the isotropic hardening, the Armstrong-Frederick model still offers the most appropriate reference for a temperature-dependent nonlinear elastoplastic simulation. 


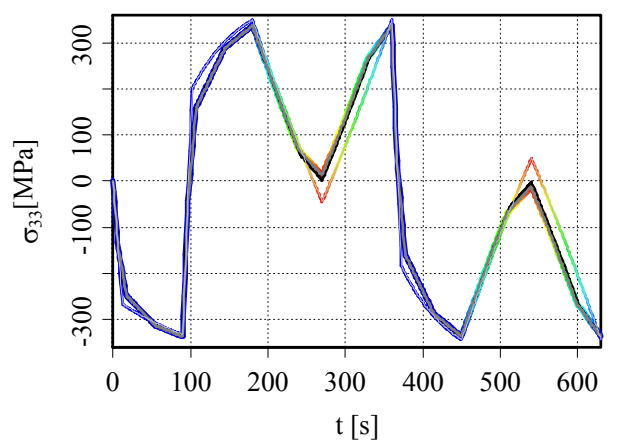

a)

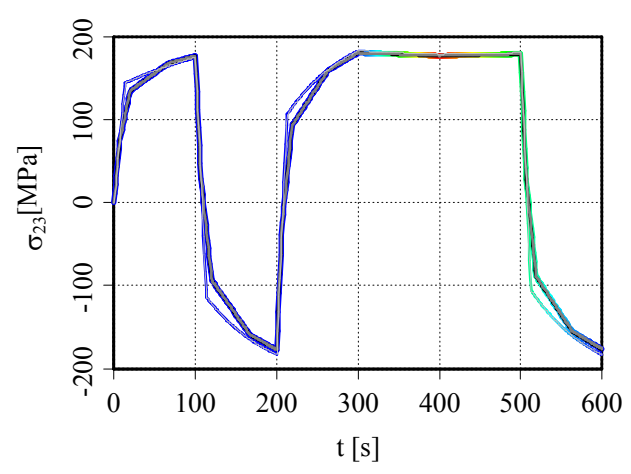

c)
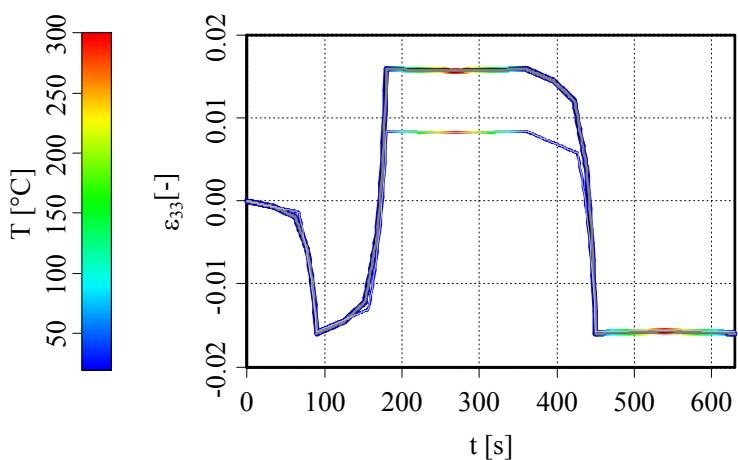

b)
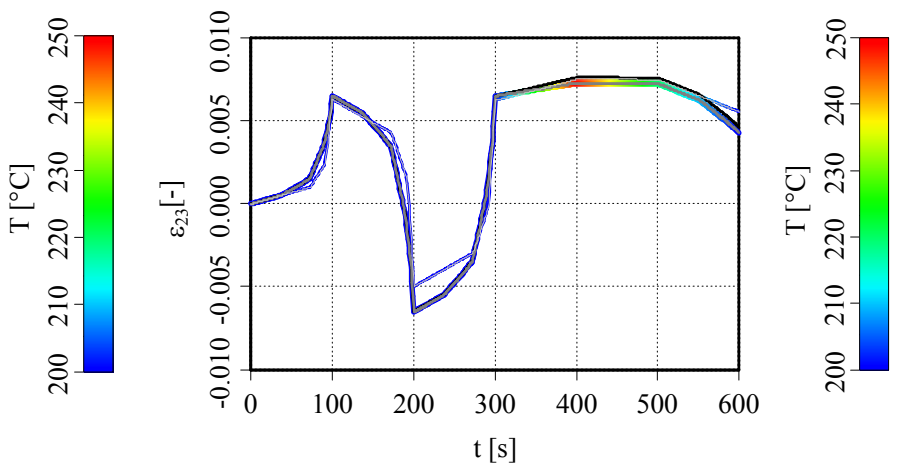

Figure 6: a) Stress response of a single finite element thermomechanically loaded by tension and compression displacement, b) strain response of a single finite element thermomechanically loaded by tension and compression forces, c) stress response in a single finite element thermomechanically loaded by shear displacement and d) strain response in a single finite element thermomechanically loaded by a shear force. The thick grey (thick coloured) line represents the result using the Prandtl model, the black line represents the result using Reference model 1 and the thin grey (thin coloured) line represents the result using Reference model 2. 


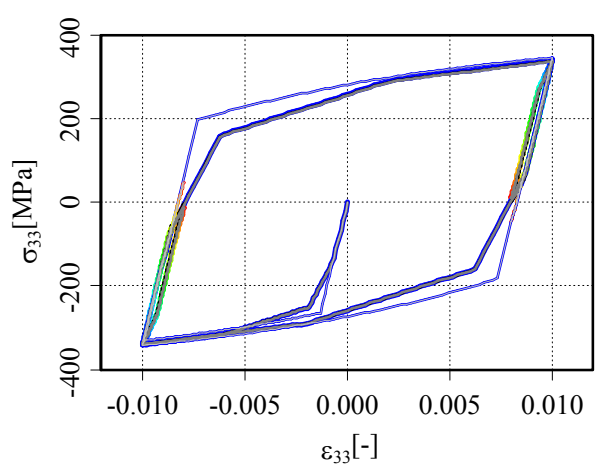

a)

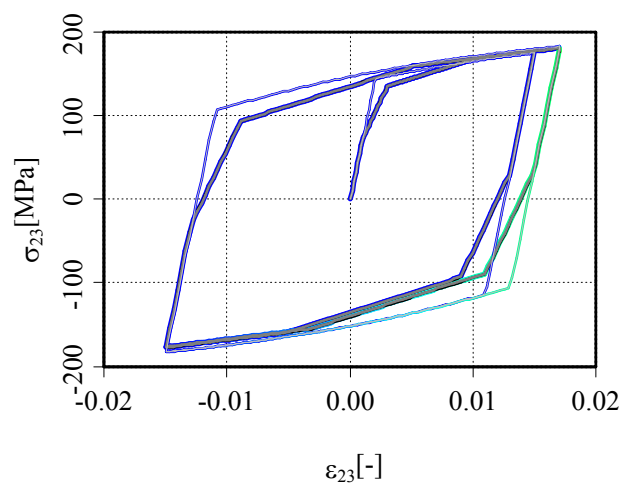

c)
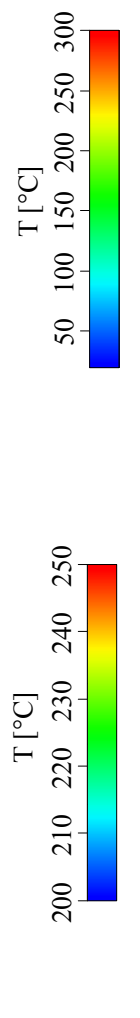

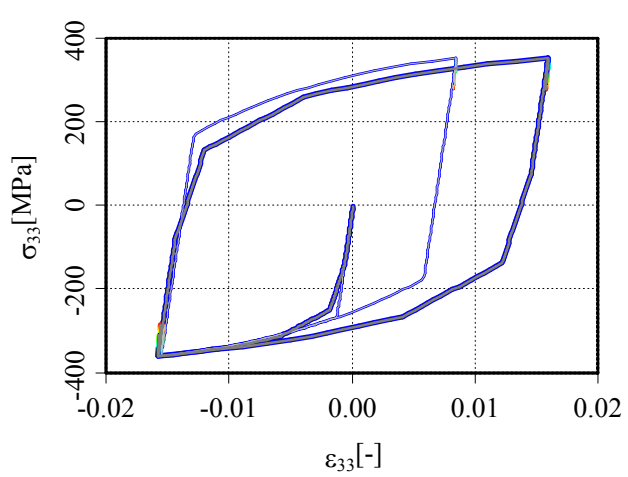

b)
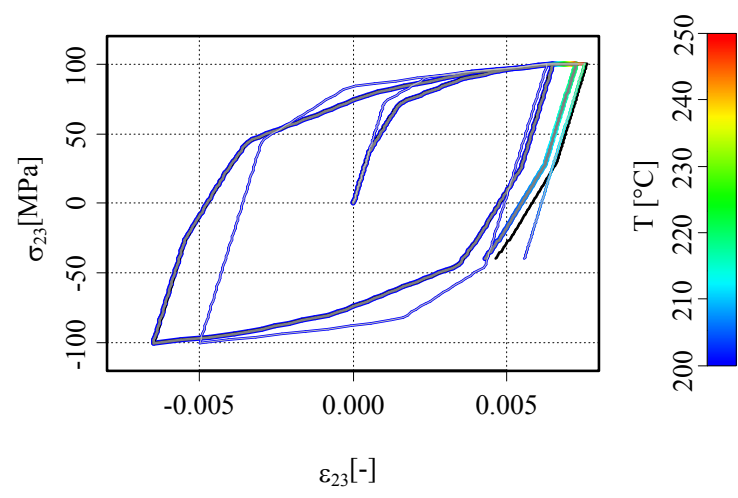

Figure 7: a) Stress-strain response of a single finite element thermomechanically loaded by tension and compression displacement, b) stress-strain response of a single finite element thermomechanically loaded tension and compression forces, c) stress-strain response in a single finite element thermomechanically loaded by shear displacement and d) stress-strain response in a single finite element thermomechanically loaded by a shear force. The thick grey (thick coloured) line represents the result using the Prandtl model, the black line represents the result using Reference model 1 and the thin grey (thin coloured) line represents the result using Reference model 2. 

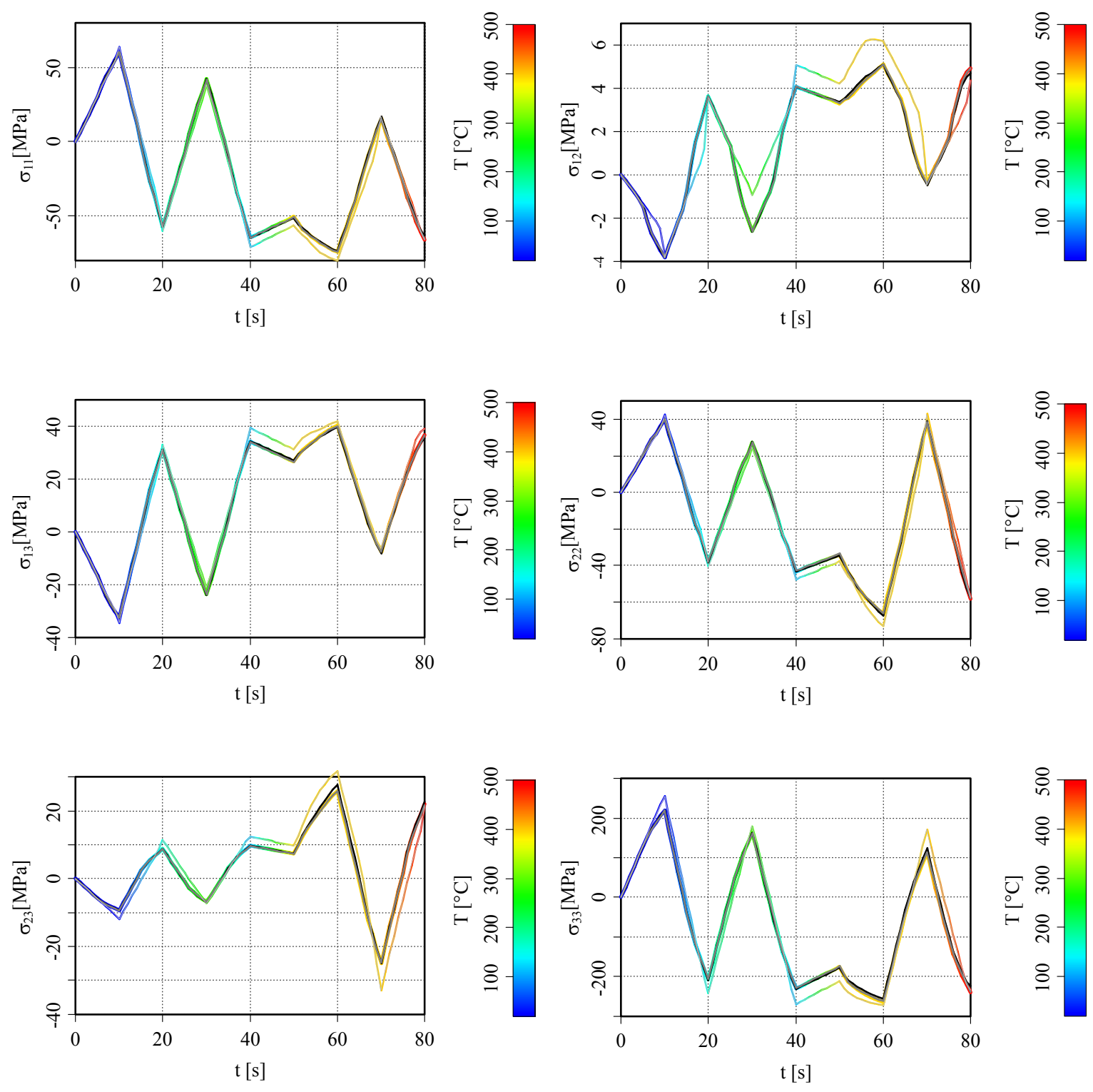

Figure 8: Stress components in element 136 of the thermomechanically displacement-loaded cantilever beam. The thick grey (thick coloured) line represents the result using the Prandtl model, the black line represents the result using Reference model 1 and the thin grey (thin coloured) line represents the result using Reference model 2. 

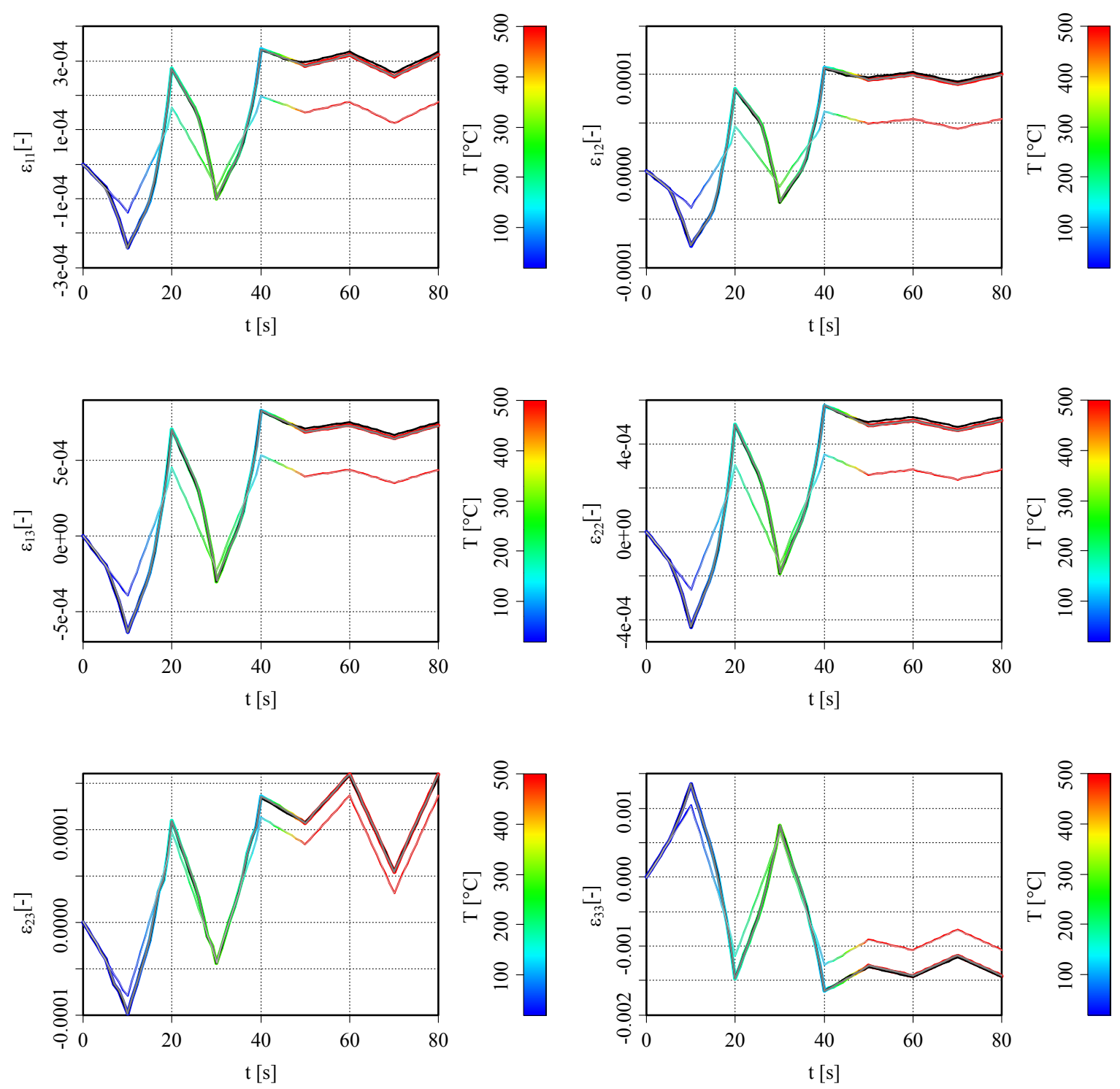

Figure 9: Strain components in element 136 of the thermomechanically force-loaded cantilever beam. The thick grey (thick coloured) line represents the result using the Prandtl model, the black line represents the result using Reference model 1 and the thin grey (thick coloured) line represents the result using Reference model 2. 

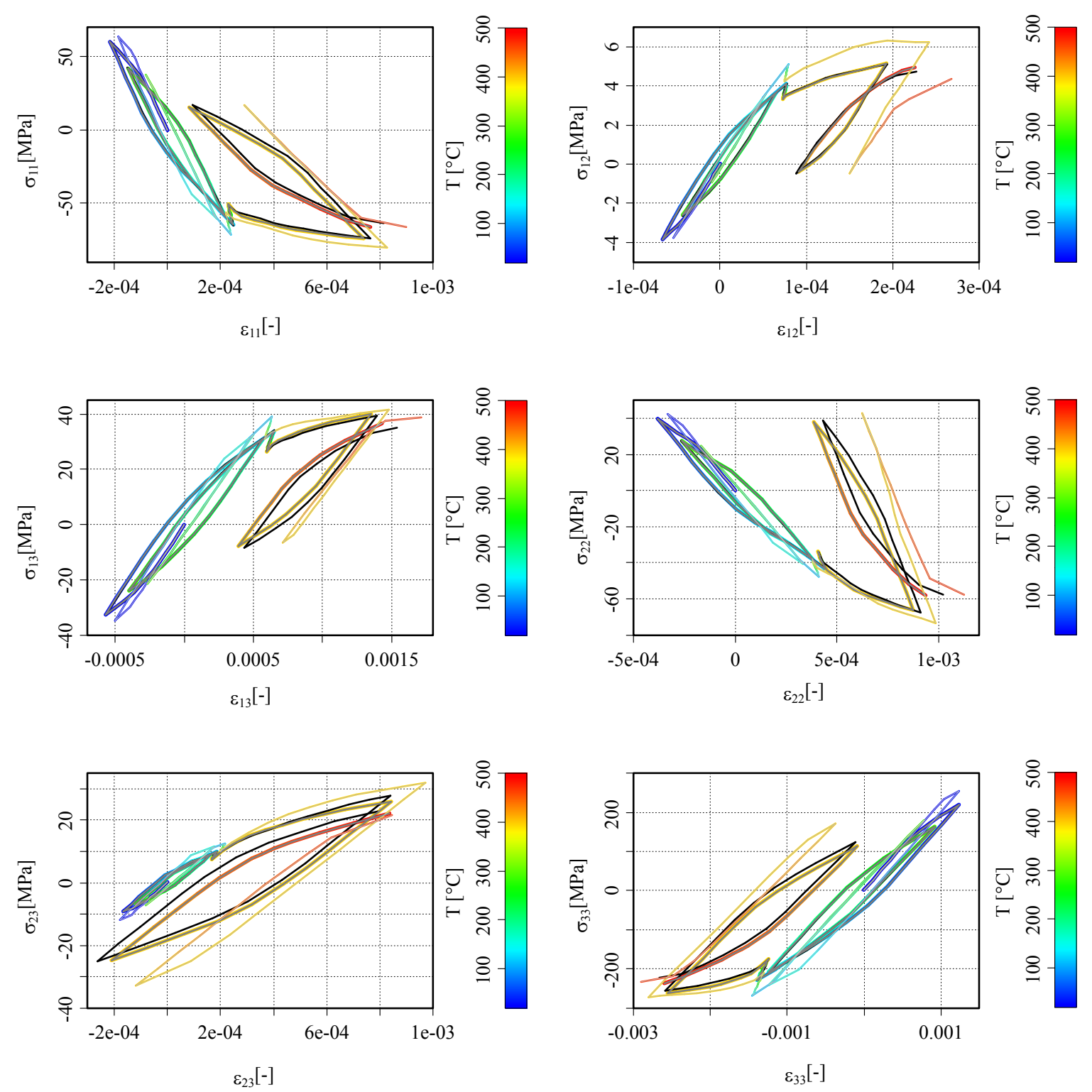

Figure 10: Stress-strain response in element 136 of the thermomechanically displacement-loaded cantilever beam. The thick grey (thick coloured) line represents the result using the Prandtl model, the black line represents the result using Reference model 1 and the thin grey (thin coloured) line represents the result using Reference model 2. 

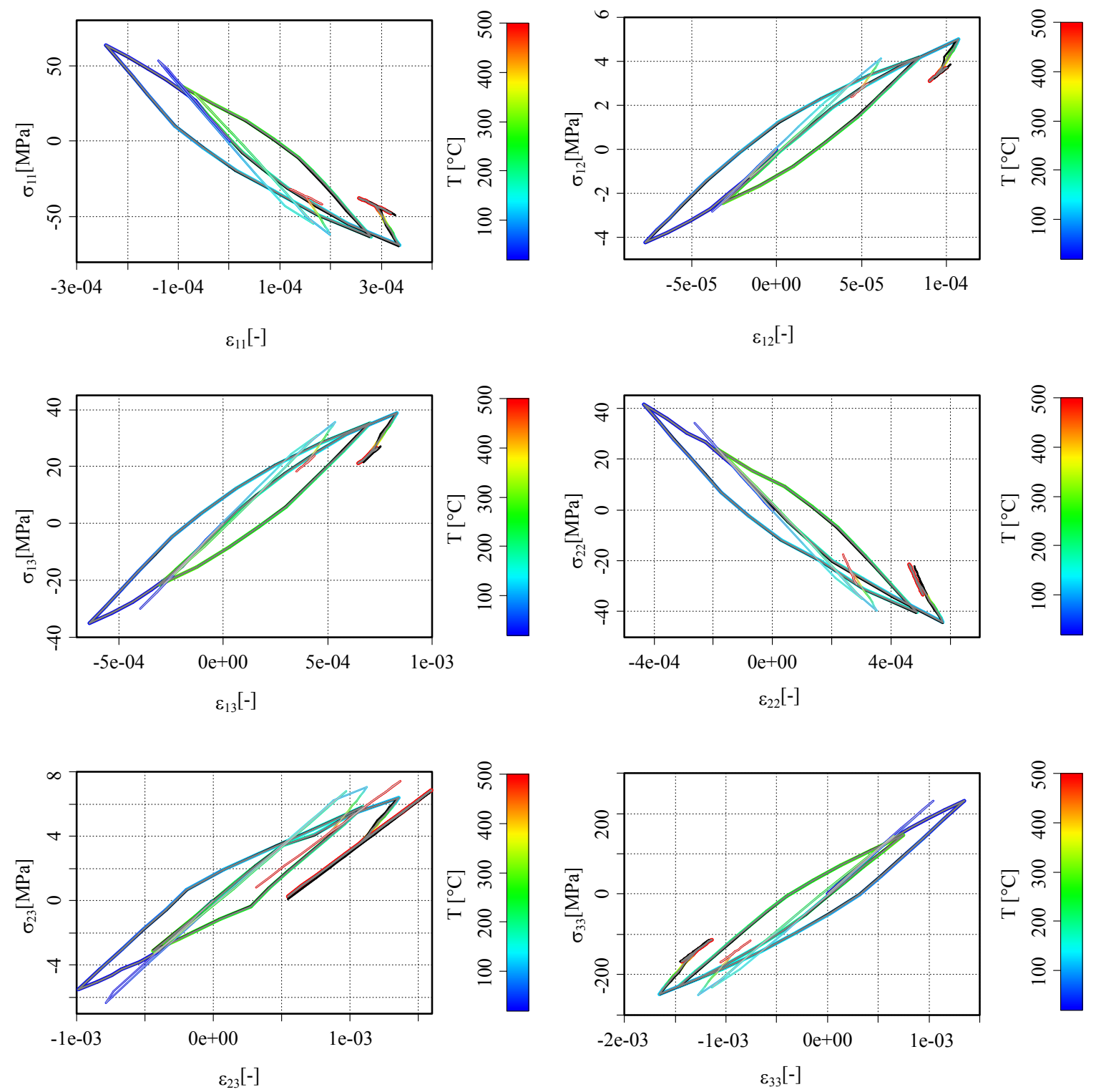

Figure 11: Stress-strain response in element 136 of the thermomechanically force-loaded cantilever beam. The thick grey (thick coloured) line represents the result using the Prandtl model, the black line represents the result using Reference model 1 and the thin grey (thin coloured) line represents the result using Reference model 2. 


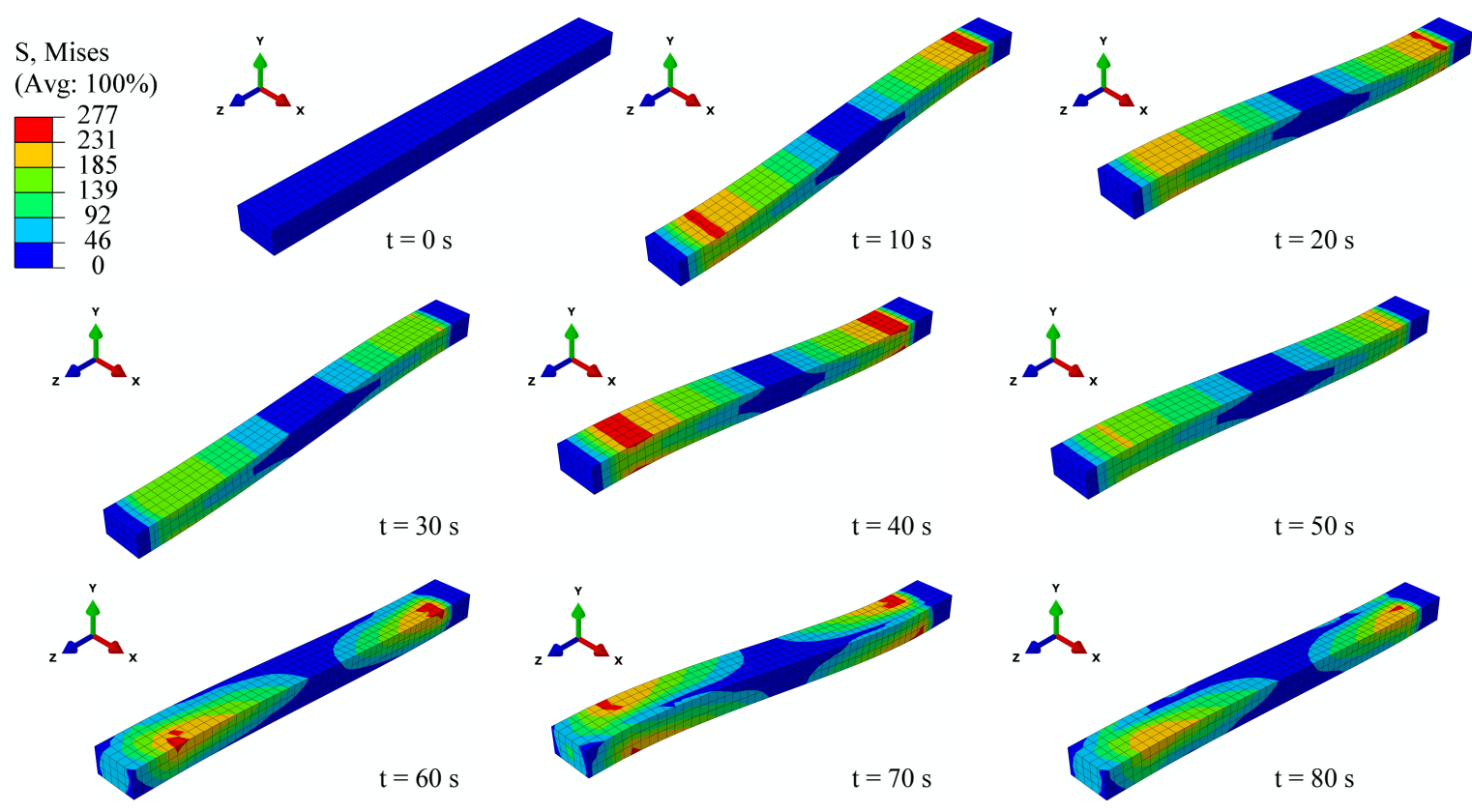

Figure 12: Magnified shape change $(\times 10)$ and the equivalent stress field in the displacement-loaded cantilever beam for each load step.

The loads of both the single elements and the cantilever beam have been chosen so as to show the behaviour of the material when it is subjected to variable thermomechanical conditions. The values of mechanical loads were then set so as to ensure an elastoplastic response of the material, and thermal loads have covered the range of experimental temperature levels (Table 1).

If the results for simple loadings are compared first, i.e. tension-compression and shear, it is observed that the results of the Prandtl model and Reference model 1 can differ to some extent due to the influence of temperature (Figs. 6 and 7). Conversely, the results using the Prandtl model and Reference model 2 follow the same trend, although they do not match completely. The reasons for such behaviour lie first in the difference between the temperature dependent stress-strain curves of the RO and the AF models (Fig. 5). The elastic region of the AF model is defined by one of the coefficients $\left(R_{0}\right)$ which is searched for during the optimisation procedure. As a result of the optimisation, the cyclic curves can deviate in the initial plastic region if the two curves must minimally deviate over the whole region between the yield stress and the tensile strength [41]. On the contrary, the RO equation in its original form does not contain an explicit proportional limit. However, if the material in the simulation is required to return to an initial stress-free state after application of small mechanical loads, then a proportional limit also has to be defined 
Table 2: Comparison of the computational times using the Prandtl and the reference models.

\begin{tabular}{lcccccc}
\hline & \multicolumn{3}{c}{ CPU time [s] } & \multicolumn{3}{c}{ Wall-clock time [s] } \\
Example & Prandtl & Ref. 1 & Ref. 2 & Prandtl & Ref. 1 & Ref. 2 \\
\hline Single element - displacement-controlled tension-compression load & 6.7 & 6.8 & 7.5 & 11 & 11 & 12 \\
Single element - force-controlled tension-compression load & 6.9 & 7.1 & 8.2 & 12 & 12 & 13 \\
Single element - displacement-controlled shear load & 6.8 & 6.9 & 7.4 & 11 & 11 & 12 \\
Single element - force-controlled shear load & 6.9 & 7.2 & 7.5 & 12 & 11 & 12 \\
Cantilever beam - displacement-controlled load & 16.0 & 24.6 & 12.6 & 18 & 26 & 15 \\
Cantilever beam - force-controlled load & 13.6 & 21.5 & 10.9 & 15 & 23 & 13 \\
\hline
\end{tabular}

for the Prandtl model. The corresponding values for the materials used for the examples are given in Table 1. Secondly, the combined AF model describes the hardening behaviour of the material differently as compared to the RO model. As the equivalent plastic strain always accumulates regardless of the loading direction, the elastic region of the AF material model increases, whilst using the Prandtl model (RO curve) the size of the elastic region does not change even if the material is loaded beyond the yield stress as only kinematic hardening is considered. In the case of displacement-controlled loading between equal but oppositely signed strain levels (Fig. 4a), this difference can be seen as an increase in the absolute stress level using Reference model 2 for times of $90 \mathrm{~s}$ and $180 \mathrm{~s}$ for tension-compression displacement (Fig. 6a). The same effect can be seen for force-controlled loading between equal but oppositely signed stress levels (Figs. 4b and 4d) where a difference in the absolute strain level is observed at $90 \mathrm{~s}$ and $180 \mathrm{~s}$ for the tensioncompression force (Fig. 6b) and at $10 \mathrm{~s}$ and $20 \mathrm{~s}$ for the shear force (Fig. 6d). Using the Prandtl model, the same stress and strain absolute levels are reached in the case of displacement-controlled and forcecontrolled loading between equal but oppositely signed load levels, respectively (Figs. 6 and 7), which proves the required stabilised cyclic behaviour, as shown in Fig. 1d. During the initial load for any of the single-element examples, the same stress-strain level is achieved regardless of the material model used as in the first step, isotropic, kinematic or combined isotropic-kinematic material models provide the same result. The only difference is in the shape of the curve which follows either the input RO curve or the input AF curve for a given temperature. Finally, the temperature influence is more expressed using the Prandtl model and Reference model 1 which is again a consequence of different cyclic curves between the material models. Nevertheless, especially during the displacement-controlled tension-compression loading, the stress values vary between equal limits using any of the models (e.g. $180 \mathrm{~s}$ and $360 \mathrm{~s}$ in Figs. 6a and 7a). 
However, the stress-strain shapes of these variations differ. Using the Prandtl model, the material already reaches beyond the yield at $300{ }^{\circ} \mathrm{C}$ and creates a nested hysteresis loop, whereas using Reference model 2 , the material remains in the elastic region so the shape of the variation is collinear with the bigger hysteresis loop (Fig. 7a).

For validation of the Prandtl model subjected to multiaxial loadings, element 136 is chosen as its position lies in the vicinity of the fixed part of the cantilever beam where the highest stresses occur (Fig. 3). As any finite element and its stress-strain response between the point of the load input and the position of the observed finite element affects the load transferred to the observed element, the stress-strain response using the Prandtl model will differ especially from the stress-strain response using Reference model 2 even in the first step. This can be seen in Figs. 8 and 9 for any stress or strain component at a time of $10 \mathrm{~s}$ or if the curves are compared in stress-strain space (Figs. 10 and 11). As the equivalent von Mises stress reaches the yield earlier using the Prandtl model and Reference model 1, the values of the stress field over the cantilever beam are lower as compared to the values using Reference model 2. Consequently, the resulting strains are higher using the Prandtl model and Reference model 1. As the material is subjected to yielding once the yield stress has been reached, any component of the stress and strain tensors from that time instant onwards exhibits a nonlinear hardening behaviour although the absolute values of that particular stress-strain component would correspond to the elastic region of the material, e.g. component $\sigma_{23}$ in Fig. 8. This is a consequence of the flow direction (Eq. 11) which regulates the size of the increment for every component of the stress and strain tensors.

Regardless of the different stress-strain values using the three models, it is observed that the phenomenon of temperature-dependent cyclic behaviour can be modelled using the Prandtl model. The consideration of the Masing and the memory rules for variable temperatures can be obtained for the displacementcontrolled loading of the cantilever beam if the stress-strain path is followed for component $\sigma_{33}$ in Fig. 10. For a temperature variation between $400{ }^{\circ} \mathrm{C}$ and $500{ }^{\circ} \mathrm{C}$, a closed hysteresis loop can be seen at the end of the stress-strain path. Similarly, at a strain of approximately -0.012 the hysteresis loop, which had started at that strain, has reached the same strain again. The stress after the closure of the hysteresis loop however differs from the stress at the start of this hysteresis loop as the temperature, which varied during the cycle, is not the same at the beginning and the end (Fig. 4e). The same observations are made for the other stress-strain components given in Figs. 8, 9, 10 and 11. Regardless of the complex temperature-dependent stress-strain behaviour, the simulation using the Prandtl model does enable a description of the phenomenon. 
As the signed von Mises criterion has been chosen to determine the equivalent plastic strain increment controlling the back-strains in Eq. 14, an incorrect sign determination can cause numerical difficulties in the simulation. A negligible load causing the volume change of a loaded finite element allows numerical difficulties to be avoided which could be the case for pure shear loads.

In Table 2 the central processing unit (CPU) times using the Prandtl model are between 1.5 and $4 \%$ lower than using Reference model 1 and between 8 and $16 \%$ lower than using Reference model 2 for a single element regardless of the loading direction. These computational times have been met on a 64-bit operating system using an Intel Core i7-4790 $3.60 \mathrm{GHz}$ processor with $16 \mathrm{~GB}$ of RAM. As the cyclic curve for the Prandtl model and Reference model 1 lies beneath the cyclic curve for Reference model 2, the plastic part of the method is entered earlier (Eqs. $11-23$ ). The number of iterations for the equivalent plastic increment is then higher which consequently lengthens the computational time using the Prandtl model. Even so, shorter CPU times can be achieved using the Prandtl model and Reference model 1 for a single element. The same reason increases the CPU times of the Prandtl model and Reference model 1 in case of the cantilever beam. As the plastic area of the material contains more elements for the Prandtl model and Reference model 1, the number of iterations to reach the equilibrium state considerably increases as compared to the simulation using Reference model 2. Consequently, the CPU time increases by about $25 \%$ for the simulation of the loaded cantilever beam. The CPU time is also affected by an advantage of the Prandtl model in that the material coefficients of the RO curve, $E, K^{\prime}$ and $n^{\prime}$ can vary with temperature. Here, the cyclic exponent $n^{\prime}$ varied from 0.12 at $20{ }^{\circ} \mathrm{C}$ to 0.03 at $650{ }^{\circ} \mathrm{C}$ which drastically changes the shape of the cyclic curve (Fig. 5). This option makes the material model realistically applicable as no additional equivalence conditions are needed, rather the input coefficients can be directly determined from experimental data. Although it additionally affects the CPU time, a detailed analysis of this advantage has not yet been performed. Nevertheless, comparison of CPU times between the Prandtl model and Reference model 1 shows 35 and $37 \%$ shorter CPU time for the displacement-controlled and force-controlled loaded cantilever beam, respectively. Moreover, CPU times for the simulations of the cantilever beam using the Prandtl model are comparable to those using Reference model 2. With the exception of the force-controlled shear loaded single element, similar ratios between the models are observed if wall-clock times instead of CPU times are compared. 


\section{Conclusion}

The Prandtl operator approach has been implemented into a FE solver to simulate the stress-strain behaviour of solids during loading. The analyses using the FE-implemented Prandtl model have proven that a Ramberg-Osgood description of the cyclic curve can be applied in a FE solver. Furthermore, the cyclic material stress-strain behaviour of solids including Masing and memory rules can be simulated during variable thermomechanical loading. Finally, the computational times using this Prandtl model can be reduced by as much as 35 percent when compared to the run times of analyses using the Besseling model.

\section{Acknowledgement}

The authors acknowledge financial support from the Slovenian Research Agency (research core funding No. P2-0182 entitled Development Evaluation).

\section{References}

[1] Y. Zhang, H.-Y. Jing, L.-Y. Xu, Y.-D. Han, L. Zhao, X.-S. Xie, Q.-H. Zhu, Creep Behavior and Life Assessment of a Novel Heat-Resistant Austenite Steel and Its Weldment, Acta Metallurgica Sinica (English Letters) 32 (2018) 638-650.

[2] D. Šeruga, E. Hansenne, V. Haesen, M. Nagode, Durability prediction of EN 1.4512 exhaust mufflers under thermomechanical loading, International Journal of Mechanical Sciences 84 (2014) 199-207.

[3] S. Dondapati, M. Trivedi, R. S. Dondapati, D. Chandra, Investigation on the mechanical stresses in a muffler mounting bracket using Root Cause Failure Analysis (RCFA), finite element analysis and experimental validation, Engineering Failure Analysis 81 (2017) 145-154.

[4] M. Nazir, Z. Khan, A. Saeed, K. Stokes, A predictive model for life assessment of automotive exhaust mufflers subject to internal corrosion failure due to exhaust gas condensation, Engineering Failure Analysis 63 (2016) 43-60.

[5] P. C. Mishra, S. K. Kar, H. Mishra, A. Gupta, Modeling for combined effect of muffler geometry modification and blended fuel use on exhaust performance of a four stroke engine: A computational fluid dynamics approach, Applied Thermal Engineering 108 (2016) 1105-1118.

[6] J.-M. Lee, S. Wee, J. Yun, H. Song, Y. Kim, J.-M. Koo, C.-S. Seok, Life Prediction of IN738LC Considering Creep Damage under Low Cycle Fatigue, International Journal of Precision Engineering and Manufacturing-Green Technology 5 (2018) 311-316.

[7] J. Sun, H. Yuan, Cyclic plasticity modeling of nickel-based superalloy Inconel 718 under multi-axial thermo-mechanical fatigue loading conditions, International Journal of Fatigue 119 (2019) 89-101.

[8] A. Ziaei-Asl, M. T. Ramezanlou, Thermo-mechanical behavior of gas turbine blade equipped with cooling ducts and protective coating with different thicknesses, International Journal of Mechanical Sciences 150 (2019) 656-664. 
[9] F.-D. Li, D.-G. Shang, C.-C. Zhang, X.-D. Liu, D.-H. Li, J.-J. Wang, J. Hui, Z.-G. Li, B. Chen, Thermomechanical fatigue life prediction method for nickel-based superalloy in aeroengine turbine discs under multiaxial loading, International Journal of Damage Mechanics 28 (2019) 1344-1366.

[10] J.-J. Wang, D.-G. Shang, Y.-J. Sun, L.-J. Li, D.-H. Li, Thermo-mechanical fatigue life prediction method under multiaxial variable amplitude loading, International Journal of Fatigue 127 (2019) 382-394.

[11] O. Kintzel, J. Mosler, An incremental minimization principle suitable for the analysis of low cycle fatigue in metals: A coupled ductile-brittle damage model, Computer Methods in Applied Mechanics and Engineering 200 (2011) 3127-3138.

[12] K. V. Spiliopoulos, K. D. Panagiotou, A direct method to predict cyclic steady states of elastoplastic structures, Computer Methods in Applied Mechanics and Engineering 223-224 (2012) 186-198.

[13] H. Pashazad, M. Kharazi, A peridynamic plastic model based on von Mises criteria with isotropic, kinematic and mixed hardenings under cyclic loading, International Journal of Mechanical Sciences 156 (2019) 182-204.

[14] M. Bartošak, C. Novotny, M. Španiel, K. Doubrava, Life assessment of SiMo 4.06 cast iron under LCF and TMF loading conditions, Materials at High Temperatures 36 (2019) 285-295.

[15] E. Silvestre, J. Mendiguren, L. Galdos, E. S. de Argandoña, Comparison of the hardening behaviour of different steel families: From mild and stainless steel to advanced high strength steels, International Journal of Mechanical Sciences 101-102 (2015) 10-20.

[16] E. Haibach, Betriebsfestigkeit - Verfahren und Daten zur Bauteilberechnung, Springer-Verlag Berlin Heidelberg, 2006.

[17] S. Roescher, M. Knobloch, Towards a prognosis of fatigue life using a Two-Stage-Model, Steel Construction 12 (2019) 198-208.

[18] M. Nagode, F. Zingsheim, An online algorithm for temperature influenced fatigue life estimation: strain-life approach, International Journal of Fatigue 26 (2004) 155-161.

[19] J. Klemenc, M. Fajdiga, Joint estimation of E-N curves and their scatter using evolutionary algorithms, International Journal of Fatigue 56 (2013) 42-53.

[20] F. D. Angelis, R. L. Taylor, An efficient return mapping algorithm for elastoplasticity with exact closed form solution of the local constitutive problem, Engineering Computations 32 (2015) 2259-2291.

[21] D. Šeruga, M. Nagode, J. Klemenc, Eliminating friction between flat specimens and an antibuckling support during cyclic tests using a simple sensor, Measurement Science and Technology 30 (2019) 095102.

[22] V. Fohrmeister, A. Bartels, J. Mosler, Variational updates for thermomechanically coupled gradient-enhanced elastoplasticity-Implementation based on hyper-dual numbers, Computer Methods in Applied Mechanics and Engineering 339 (2018) 239-261.

[23] E. Melan, Zur Plastizität des räumlichen Kontinuums, Ing. Arch. 9 (1938) 116-126.

[24] D. W. Prager, The Theory of Plasticity: A Survey of Recent Achievements, Proceedings of the Institution of Mechanical Engineers 169 (1955) 41-57.

[25] W. Prager, A New Method of Analyzing Stresses and Strains in Work-Hardening Plastic Solids, Journal of Applied Mechanics 23 (1956) 493-496.

[26] H. Ziegler, A modification of Prager's hardening rule, Q. Appl. Math. 17 (1959) 55-65.

[27] J. Besseling, A theory of elastic, plastic and creep deformations of an initially isotropic material, Journal of Applied Mechanics 25 (1958) 529-536. 
[28] P. J. Armstrong, C. O. Frederick, A mathematical representation of the multiaxial Bauschinger effect, Tech. rep., Report RD/B/N731, CEGB, Central Electricity Generating Board, Berkley, UK. (1966).

[29] J. Chaboche, Constitutive equations for cyclic plasticity and cyclic viscoplasticity, International Journal of Plasticity 5 (1989) 247-302.

[30] N. Ohno, J.-D. Wang, Kinematic hardening rules with critical state of dynamic recovery, part I: formulation and basic features for ratchetting behavior, International Journal of Plasticity 9 (1993) 375-390.

[31] N. Ohno, J.-D. Wang, Kinematic hardening rules with critical state of dynamic recovery, part II: Application to experiments of ratchetting behavior, International Journal of Plasticity 9 (1993) 391-403.

[32] H. Rokhgireh, A. Nayebi, J. Chaboche, Application of a new distortional yield surface model in cyclic uniaxial and multiaxial loading, International Journal of Solids and Structures 110-111 (2017) 219-238.

[33] D. Agius, K. I. Kourousis, C. Wallbrink, A modification of the multicomponent Armstrong-Frederick model with multiplier for the enhanced simulation of aerospace aluminium elastoplasticity, International Journal of Mechanical Sciences 144 (2018) $118-133$.

[34] J.-Y. Lee, M.-G. Lee, F. Barlat, G. Bae, Piecewise linear approximation of nonlinear unloading-reloading behaviors using a multi-surface approach, International Journal of Plasticity 93 (2017) 112-136.

[35] M. Nagode, M. Fajdiga, Coupled elastoplasticity and viscoplasticity under thermomechanical loading, Fatigue \& Fracture of Engineering Materials \& Structures 30 (2007) 510-519.

[36] W. Ramberg, W. R. Osgood, Description of stress-strain curves by three parameters, Tech. rep., NACA-TN-902 (1943).

[37] M. Nagode, F. Laengler, M. Hack, A time-dependent damage operator approach to thermo-mechanical fatigue of Ni-resist D-5S, International Journal of Fatigue 33 (2011) 692-699.

[38] M. Nagode, D. Šeruga, Fatigue life prediction using multiaxial energy calculations with the mean stress effect to predict failure of linear and nonlinear elastic solids, Results in Physics 6 (2016) 352-364.

[39] B. Kozjek, D. Seruga, T. Pepelnjak, M. Nagode, Fatigue life prediction of brass ball forging tool, Materials Today: Proceedings 4 (2017) 5855-5860.

[40] A. Gosar, M. Nagode, S. Oman, Continuous fatigue damage prediction of a rubber fibre composite structure using multiaxial energy-based approach, Fatigue \& Fracture of Engineering Materials \& Structures 42 (2019) 307-320.

[41] D. Šeruga, M. Nagode, Comparative analysis of optimisation methods for linking material parameters of exponential and power models: An application to cyclic stress-strain curves of ferritic stainless steel, Proceedings of the Institution of Mechanical Engineers, Part L: Journal of Materials: Design and Applications 233 (2018) 1802-1813.

[42] F. E. Karaoulanis, Implicit Numerical Integration of Nonsmooth Multisurface Yield Criteria in the Principal Stress Space, Archives of Computational Methods in Engineering 20 (2013) 263-308.

[43] M. Safaei, M.-G. Lee, W. D. Waele, Evaluation of stress integration algorithms for elastic-plastic constitutive models based on associated and non-associated flow rules, Computer Methods in Applied Mechanics and Engineering 295 (2015) 414-445.

[44] R. Esmaeilpour, H. Kim, T. Park, F. Pourboghrat, B. Mohammed, Comparison of 3D yield functions for finite element simulation of single point incremental forming (SPIF) of aluminum 7075, International Journal of Mechanical Sciences 133 (2017) 544-554.

[45] M. A. Meggiolaro, J. T. P. de Castro, H. Wu, A general class of non-linear kinematic models to predict mean stress relaxation and multiaxial ratcheting in fatigue problems - Part I: Ilyushin spaces, International Journal of Fatigue 82 (2016) 158-166. 
[46] J. Ding, G. Kang, Y. Zhu, M. Zhu, Finite element analysis on bending fretting fatigue of 316L stainless steel considering ratchetting and cyclic hardening, International Journal of Mechanical Sciences 86 (2014) 26-33.

[47] A. A. Roostaei, H. Jahed, A cyclic small-strain plasticity model for wrought Mg alloys under multiaxial loading: Numerical implementation and validation, International Journal of Mechanical Sciences 145 (2018) 318-329.

[48] A. Pradeau, S. Thuillier, J. Yoon, Prediction of failure in bending of an aluminium sheet alloy, International Journal of Mechanical Sciences 119 (2016) 23-35.

[49] Dassault Systèmes, Writing User Subroutines with Abaqus, DS SIMULIA, 2009. 